\title{
Temporal and Spatial Evolution of China's Human Development Index and Its Determinants: An Extended Study Based on Five New Development Concepts
}

\author{
Chengjun Liu $^{1}$ (D) Fuqiang Nie ${ }^{1} \cdot$ Dong Ren ${ }^{1}$
}

Accepted: 5 February 2021 / Published online: 6 March 2021

(C) The Author(s), under exclusive licence to Springer Nature B.V. 2021

\begin{abstract}
This paper innovatively expands China's human development index under the background of development concept in the new era, constructs the index system of China's human development index (CHDI) with four core dimensions of "life span, education, income and sustainable development" and measures the human development level of 31 provinces and the whole country from 1990 to 2017. Using the method of exploratory spatial data analysis (ESDA), this paper studies the spatiotemporal evolution characteristics of CHDI in 31 provinces from 1990 to 2017 and discusses the mechanism of CHDI in China. The results show that: (1) CHDI in eastern China is obviously ahead of other regions and there is a big gap in human development among different regions. CHDI of 31 provinces had positive spatial correlation, showing significant spatial aggregation effect. (2) In addition to its own influencing factors, the CHDI of a province is also affected by the CHDI of its "neighboring" provinces. (3) Urbanization rate, per capita financial expenditure on education and the number of health professionals are the three main positive driving factors of China's CHDI and the per capita carbon emission is the main reverse driving factor. This study provides policy suggestions for improving the level of human development in China and realizing regional balanced development.
\end{abstract}

Keywords Human development index $\cdot$ New development concept $\cdot$ Sustainable development $\cdot$ Space-time analysis $\cdot$ Spatial autoregressive model

Chengjun Liu

liuchengjun19831119@126.com

Fuqiang Nie

510000828@qq.com

Dong Ren

rd7764@163.com

1 School of Statistics, Southwestern University of Finance and Economics, No.555, Liutai Road, Wenjiang District, Chengdu 611130, China 


\section{Introduction}

Economists generally believe that the evolution of human development concept has gone through three stages. In the first stage, economic growth is equated with development, with GDP or GNP as the evaluation index. The second stage of development concept is that, in addition to economic growth, structural improvement and social progress are required. The most representative evaluation indicator is the Human Development Index (HDI) developed by the United Nations Development Programme (UNDP) in 1990. The third stage of the development concept requires economic growth, structural improvement, social progress and the ability of future generations not to be destroyed, that is, sustainable development, mainly taking green GDP as the evaluation index (Dietz et al. 1997; Ge 2004; Ozturk et al. 2010; Li et al. 2020). The Human Development Index (HDI) was proposed in the human development report 1990 issued by the United Nations Development Programme (UNDP). It aims to measure the achievements of a country or region in three basic aspects: healthy longevity, knowledge acquisition and decent life (UNDP 1990). As an index to measure human well-being, HDI overcomes the shortcomings of single index such as GDP or GNP in the past and then retains the advantages of simple calculation. The index has not only been accepted by academics, policy makers, government departments and development agencies, but has also become a means of comparing levels of human development between countries (Sanusi 2008).

Before the introduction of the HDI by UNDP, measures of development focused either on income indicators or social indicators. The HDI has clear advantages as a composite index for measuring human development. However, it is still criticized by many researchers. For example, Zhu (2011) argued that the HDI does not capture all aspects of human well-being and lacks consideration of the diversity of factors that influence human development. In addition to the three dimensions of "life span, income and education", there are many other choices highly valued by people. Sen et al. (1994) argued that countries at different stages of development usually face different problems of human development. The higher the stage of development, the higher the level of needs. The choice of representative indicators for measuring human development should vary between countries at different stages of development. In other words, the traditional indicators contained in the HDI should be supplemented with new indicators as appropriate. UNDP has made several improvements to the HDI after receiving suggestions from several researchers, including the adjustment of indicator thresholds, the replacement of indicators in the education dimension, the methodological adjustment of the aggregated sub-index to the HDI and the addition of some auxiliary indicators. In addition to the UNDP, a number of researchers have made various forms of improvements to HDI (Zhou et al. 2010; Taner et al. 2011; Bilbao-Ubillos 2013; Tofallis 2013; Sayed et al. 2018). Nevertheless, the HDI still has some shortcomings. For example, the HDI is very sensitive to the selection of thresholds for each indicator, the choice of equal weights for sub-indices is too subjective, some important descriptions of well-being are not included (e.g., inequality in income distribution, gender inequality and unequal distribution of health resources) and the sustainability of development is not considered (Sayed et al. 2015; Nikolaos et al. 2019; Lind 2019). This paper attempts to improve on some of these shortcomings, such as inequality and sustainability issues, when measuring China's human development within the context of the five development concepts.

Inequalities in human development are being taken more and more seriously. As the current COVID-19 pandemic demonstrates, inequalities in health resources and health 
services have a major impact on human life and death, which seriously threatens the sustainability of human development. It is therefore essential to consider developmental inequalities when measuring the level of human development in a country or region. The three core dimensions of "life span, education and income" in HDI are defined in terms of their average achievement, but without considering their distribution within a country or region. In fact, many modern growth processes show that inequality continues to rise despite declining poverty levels. In China, for example, income inequality has continued to worsen over the period 1990-2017, despite an average annual growth rate of $11 \%$ in GNI per capita. China's Gini coefficient exceeded 0.46 in 2017, exceeding the internationally accepted cautionary threshold of 0.40. Similarly, there are inequalities in the distribution of educational and medical resources. Inequality in human development has been noted early but not given enough attention. Anand et al. (1994) proposed to use the Gini coefficient to adjust the income index for inequality and then aggregate it with the life expectancy index and education index to form the HDI index. Hicks (1997) used Anand et al. (1994) principle of inequality measurement to inequality-adjust the three dimensions of income, education and health, which were then aggregated into the new Human Development Index (IAHDI). Foster et al. (2005) further considered the inequality between the three dimensions of "life span, education and income" and then constructed another new HDI. UNDP (2010) drew on Atkinson's (1970) model of inequality measurement to inequality-adjust the three dimensions of "life span, education and income" and then aggregates them into an inequality-adjusted human development index (IHDI). Since 2010, the IHDI has been published in the Human Development Report as a complementary index to the HDI. This paper therefore makes inequality adjustments for the three dimensions of "life span, education and income" when measuring China's level of human development.

The sustainability of global human development is currently being challenged as never before, as past developments have led to the emergence of a series of problems such as the continuing deterioration of global environmental pollution, the increasing scarcity of natural resources and uncoordinated development between regions. Unsustainable human development is not true human development. Unfortunately, UNDP did not consider the issue of sustainability of development when it proposed the Human Development Index in 1990. Also, most studies on human development and sustainable development are separate. Neumayer (2001) suggested that human development in a country may be unsustainable if the net devaluation of its manufacturing and natural capital stock is greater than its investment. Neumayer's analysis of 155 countries shows that human development is unsustainable in 42 countries, most of which have a low HDI. This means that countries with a low HDI may not be able to sustain development in the future. Neumayer (2012) made recommendations on how to combine the measurement of human development with the measurement of sustainability and then conducted empirical research using data from 1980 to 2006. The results show that, on the one hand, many countries with a low HDI also face weak unsustainability; on the other hand, countries with a high HDI typically exhibit strong unsustainability. The measurement of the ecological footprint reveals that the strong unsustainability problem is mainly due to the large amount of $\mathrm{CO} 2$ emissions. Bucher (2016) studied the impact of HDI and environmental conditions on sustainable development in 178 countries and analyzed the spatial differences in the sustainability of these countries. The study shows that high or very high developed countries are at the forefront of sustainable development capacity. In order to address the issue of sustainability not being described in the Human Development Index, UNDP has added indices of environmental sustainability, economic sustainability and social sustainability to the Human Development Report (UNDP 2016). However, the UNDP does not incorporate sustainability issues directly into 
the HDI. In order to compensate for the shortcomings of not including sustainability in the Human Development Index and to reflect the current requirements of China's five development concepts, this paper will construct the fourth core dimension of human development in China - the sustainable development dimension - in addition to the three core dimensions of life span, education and income, based on the five development concepts.

The five development concepts of "innovation, coordination, green, openness and sharing" put forward in the report of the 19th National Congress of the People's Republic of China are intended to adapt to the "new normal" of China's economy shifting from a highspeed growth model to a high-quality development model. With the five development concepts as the guiding ideology, China's economic development will be transformed from an extensive development model to a high-quality development model and ultimately achieve the goal of sustainable human development. In the context of the five development concepts, people not only have the need to choose between living a long and healthy life, acquiring knowledge and living a decent life, but also lack the content that can promote sustainable human development, such as scientific and technological innovation, coordinated urban and rural development, environmental protection, opening up to the outside world and sharing the fruits of development. Therefore, the HDI index system established by UNDP is no longer suitable for measuring China's human development level and there is an urgent need to construct a set of human development level measurement index system that fits China's national conditions. To the best of our knowledge, researchers have studied the five development concepts and human development independently and there is a lack of literature combining the two (Zhan et al. 2016; Zhang 2018; Yang 2019). Therefore, this paper attempts to construct a chinese human development index (CHDI) indicator system that can reflect sustainable development based on the five development concepts of "innovation, coordination, green, openness and sharing" and the HDI indicator system. China's level of human development is then measured according to the CHDI index system.

In order to be able to give policy recommendations that are conducive to the promotion of China's level of human development, this paper will also analyse the spatial and temporal evolution of China's CHDI and then conduct an empirical analysis of the CHDI to find out the important factors influencing China's CHDI and identify the key issues.

Most of the literature on analyzing the influencing factors of China's level of human development is based on traditional econometric models, while ignoring the spatial effects (Yang et al. 2005). Chen (2016) selected explanatory variables from four aspects: social wealth gap, institutional change, government spending on education and health care and then analyzed the factors influencing the level of human development in China based on panel data for 31 provinces from 1996 to 2014. Wang (2016) analyzed the driving effects of changes in human well-being in China from 1980-2010 and their temporal and spatial differentiation using the LMDI (Log-Mean Divisia Index) method. The results show that the improvement of human well-being in China in 1980-2000 was driven by both economic and technological progress effects, while the improvement of human well-being in China in 2001-2010 was mainly driven by economic effects. Wang et al. (2019) used the SDA (structural decomposition analysis) weighted average method to structurally decompose the three sub-index contributions to HDI and then further analyzed the main drivers that influenced the changes in China's HDI. The results show that the contribution of income index to China's HDI is gradually decreasing from 1982 to 2017, while the contribution of education index and health index to China's HDI is gradually increasing. Ren et al. (2020) measured China's HDI over the period 1990-2018 and analyzed the factors affecting HDI using panel data from 31 provinces over the period 1990-2018. The study found that increasing the disposable income of urban and rural residents, increasing the proportion of 
fiscal expenditure on medical expenses and increasing the urbanization rate are important ways to improve China's HDI. The above literature analysing the factors influencing the HDI is based on traditional methods and lacks consideration of spatial effects.

According to the first law of geography, things are universally connected and spatially adjacent things are more closely related to each other. Therefore, ignoring the role of spatial geographic factors in human development may bias the measurement results. Unfortunately, the literature on the spatial mechanism of HDI in China is severely lacking. Zhang (2017) tested the spatial correlation of HDI in 31 Chinese provinces over the period 1995-2015. The results show that there is a significant spatial correlation of HDI in China. Unfortunately, the literature does not further analyze the spatial mechanism of HDI in China in terms of spatial effects. Li et al. (2020) constructed an ecological input index (EII) combining the two dimensions of resource consumption and pollution emission and incorporated the EII into the HDI to construct an ecologically sensitive Chinese human development index (ECHDI). The spatial correlation and convergence of ECHDI were analyzed in the literature using ESDA methods. The results showed that spatial correlation and discrepancy of Chinese ECHDI coexisted. There was no $\alpha$ convergence but significant absolute $\beta$ convergence and conditional $\beta$ convergence in Chinese ECHDI.

From the above literature, it is evident that most of the literature has adopted traditional indicators and methods for measuring China's human development and lacked the consideration of spatial effects when analysing the factors influencing China's human development. This is the reason for constructing the CHDI indicator system and choosing the spatial measurement model to analyse the influencing factors of CHDI in this paper.

Based on the above discussion, this paper will construct the China Human Development Index (CHDI) indicator system based on the five development concepts and the HDI index system and use the CHDI index system to measure the human development level of the whole country and 31 provinces in 1990-2017. The spatial measurement model and the panel data of 31 provinces in 1990-2017 will be used to analyze the spatial and temporal evolution and determinants of China's CHDI. This paper is organized as follows. Section 2, the CHDI index system is constructed and the indicator data sources are introduced. Section 3 introduces the research methods used in this paper, including inequality measurement model, coupled coordination model, spatial correlation test and spatial panel regression model. Section 4 discusses the empirical findings. Includes CHDI measurement results, spatio-temporal evolution, convergence analysis, spatial correlation analysis, spatial regression analysis and analysis of the prediction of CHDI under different models. Section 5 presents the conclusions and policy recommendations of this paper.

\section{Index System and Data Source of CHDI}

HDI in human development report 2017 is composed of geometric averages of three core dimensions: (1) life span, measured by life expectancy at birth; (2) education, measured by arithmetic mean of expected years of education and average years of education; (3) income, measured by the logarithm of GNI (PPP dollars) per capita. Because the data units of each indicator are different, it is necessary to standardize the data of each indicator before aggregating it into HDI. Among them, the threshold of each indicator standardization is as follows. The minimum and maximum of life expectancy at birth are 20 years and 85 years, respectively. The minimum and maximum education years at birth are 0 years and 18 years, respectively. The minimum and maximum average education years of adults 
are 0 years and 15 years, respectively. The minimum and maximum values of per capita GNI are $\$ 100$ and $\$ 75,000$, respectively (UNDP 2018).

Based on the five development concepts of "innovation, coordination, green, openness and sharing", this paper constructs the fourth core dimension of China's human development index (CHDI), namely sustainable development dimension. Then, the index system of CHDI is composed of four core dimensions of life span, education, income and sustainable development. Among them, the core dimension of sustainable development consists of the geometric average of the following five sub-indexes.

1. Innovation index. Innovation is in response to the prominent contradiction between China's weak innovation capacity and the increasingly fierce global scientific, technological and economic competition. It emphasizes the question of the source of the driving force for development. Referring to the measurement indicators of innovative development concept put forward by Yang (2017), Du et al. (2017) and Hu et al. (2019), this paper selects R\&D investment intensity (total R \& D investment / GDP) and patent authorization per 10,000 people as the measurement indicators of innovative development.

2. Coordination index. The concept of coordinated development embodies the inherent law of the development of things. Human society is an "organism" composed of various factors and fields which are interrelated, restricted and transformed each other. The law of human social development depends on the integrity and interaction of "organism". The coordinated development of various "dimensions" can achieve the effect of $" 1+1>2$ ". Referring to the coordinated development measurement indicators of Zhang (2018) and Hu et al. (2019), this paper chooses three indicators to jointly measure the level of coordinated development: the ratio of per capita disposable income of urban and rural residents, the ratio of per capita consumption of urban and rural residents and the unemployment rate of urban residents. It is worth noting that in order to reflect the degree of coordination between the four core dimensions of CHDI, they should be coordinated using Eq. (4) in Sect. 3.2 before aggregating them into CHDI.

3. Green index. The concept of green development focuses on solving the problem of harmony between man and nature (Li et al. 2020). The green development concept is proposed in response to the contradiction between the serious environmental pollution, resource constraints and ecosystem degradation in China and the people's strong demand for a beautiful environment, clean air, clean drinking water and food safety ( $\mathrm{Li}$ et al. 2018). Carbon dioxide is the main culprit of greenhouse effect and the main obstacle to green development. Researchers have done a lot of research on carbon dioxide emissions (Holtz- Eakin et al. 1992; Canadelll, et al. 2007). Referring to the green development indicators of Dietz et al. (1997), Ozturk et al. (2010) and Du (2017), this paper selects carbon dioxide emission intensity (CO2 emission / GDP) and energy consumption intensity (total standard coal consumption / GDP) as the measurement indicators of green development.

4. Open index. Open development is the specific application of Marx's theory of international division of labor. Only through opening can a country achieve prosperous development. The overall level of China's opening up to the outside world is not high and its ability to make good use of both domestic and foreign markets and resources is not strong. Promoting a higher level of China's opening up to the outside world will enable China's economy to integrate more deeply into the world economy and will be conducive to the formation of a broader community of interest. Referring to the open development measurement indicators of Zhang (2018), Hu et al. (2019), this paper 
selects trade dependence (total trade import and export / GDP) and foreign investment intensity (total foreign investment / GDP) as the measurement indicators of open development.

5. Share index. The total amount of China's economic continues to increase, but the income gap continues to expand, the gap between urban and rural public service level is significant and the inequality of medical and educational resources distribution is more prominent. Shared development focuses on solving the problem of social equity and justice. Referring to the shared development measurement indicators of Yang (2017), Zhang (2018), Hu et al. (2019), this paper selects the social security level (total social security expenditure / GDP), Engel coefficient and medical service capacity as the measurement indicators of shared development.

The complete index system of CHDI is shown in Table 1.

According to the CHDI index system in Table 1, the four sub-indexes of "life span, education, income and sustainable development" are combined into the CHDI composite index. (1) In the first step, the four sub-indexes of life span, education, income and sustainable development are calculated according to the data of each indicator. (2) In the second step, inequalities in life span, education and income are adjusted for using the inequality measurement model in Sect. 3. (3) In the third step, the geometric mean of the sustainable development index, the inequality-adjusted income index, the inequality-adjusted life span index and the inequality-adjusted education index is calculated, which is the composite level of human development. (4) The fourth step is to use the coupling coordination degree model in Sect. 3 to calculate the coupling coordination of sustainable development index, inequality adjusted income index, inequality adjusted life index and inequality adjusted education index. (5) In the fifth step, the coupling coordination adjustment of comprehensive development level in the third step is carried out. That is to calculate the geometric average of the comprehensive development level in the third step and the coupling coordination degree in the fourth step to form the final CHDI index. Among them, the data of each indicator in CHDI index system come from the website of National Bureau of statistics, statistical yearbook of various departments (or industries) and statistical bulletin. Indicator thresholds in the three dimensions of life span, education and income are derived from UNDP. The maximum value of the indicator threshold in sustainable development dimension is the maximum value of 31 provinces in 2020 estimated according to the target value of the 13th five-year plan and the minimum value is the natural threshold. To make the per capita GNI, disposable income, consumption, per capita GDP, education funds and other value indicators in CHDI index system comparable in different years, this paper takes 1990 as the base period to eliminate the inflation of these indicators.

\section{Methodology}

\subsection{Inequality Measurement Model}

Based on the previous analysis, the process of calculating CHDI requires inequality adjustments for life span, education and income. This paper uses the inequality measurement model in human development report 2019 to adjust the inequality of the above three sub-indexes and the specific formula is as follows (Atkinson 1970; UNDP 2018). 


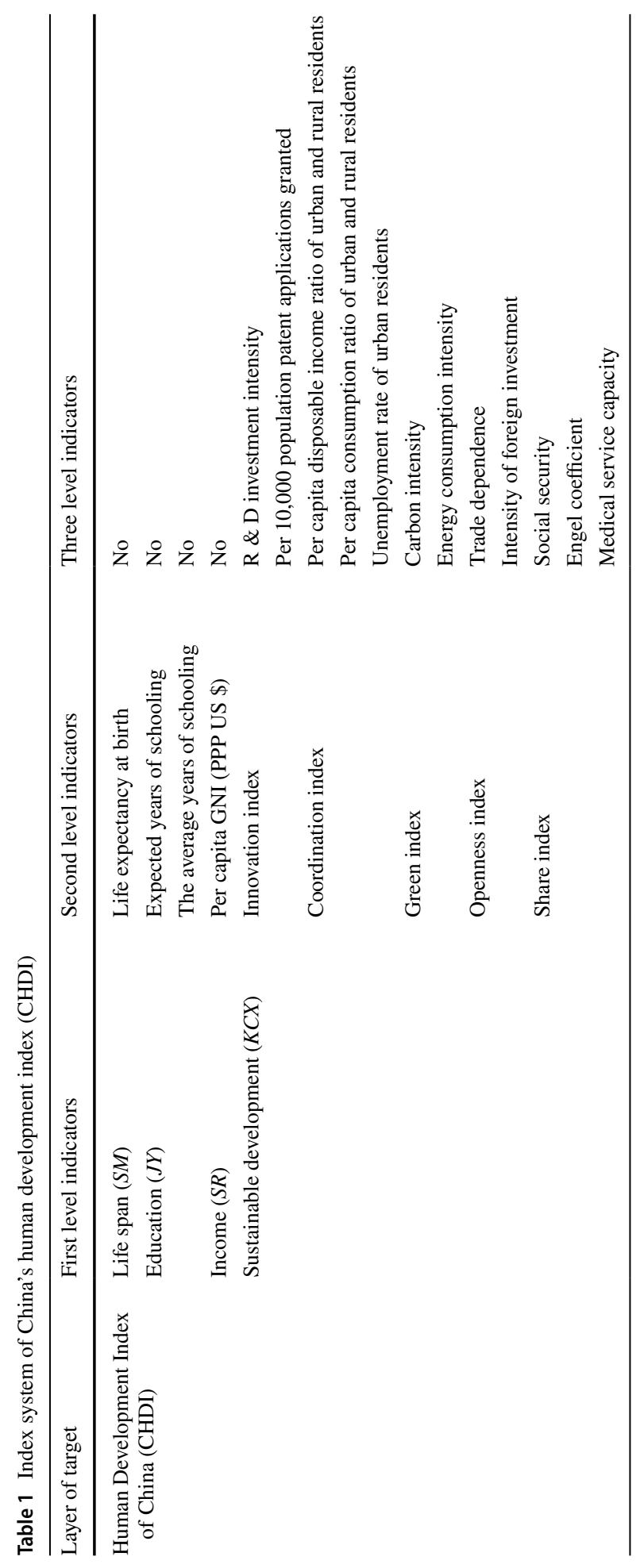


First, the inequality coefficients for each of the indicator variables in the dimensions of life span, education and income were calculated using Atkinson's inequality measurement formula (1).

$$
A_{x}=1-\frac{\sqrt[n]{X_{1} \cdots X_{n}}}{\bar{X}}
$$

where $\left\{X_{1}, \cdots, X_{n}\right\}$ denotes the potential distribution of the indicator variables $x$ in the dimensions of life span, education or income and $\bar{X}$ is their arithmetic mean. $A_{x}$ is the inequality coefficient of the indicator variable $x$ (such as life expectancy, average years of education, expected years of education and per capita GNI).

Then, the life span index, education index and income index are adjusted unequally.

$$
I_{x}^{*}=\left(1-A_{x}\right) \cdot I_{x}
$$

where $I_{x}^{*}$ is the inequality adjusted index. $I_{x}$ is the value of life span, education and income before inequality adjustment. The coefficient of inequality in education is the arithmetic mean of the inequality coefficient of expected years of education and that of average years of education.

\subsection{Coupling Coordination Model}

There are many models for measuring coordination. Among them, the coupled coordination model is widely used in the social sciences because of its clear meaning and simple calculation. The concept of coupling degree is derived from the capacity coupling coefficient in physics, which is used to describe the strength of interaction and influence between two or more systems. It has been widely used in the field of social science. The coupling coordination degree model can evaluate the interaction and influence between two or more social systems, to obtain the coordinated development level between systems. The coupling coordination degree formula is as follows (Cong 2019).

$$
C\left(u_{1}, u_{2}, \cdots, u_{n}\right)=n \times\left[\frac{u_{1} \cdot u_{2} \cdots \cdot u_{n}}{\left(u_{1}+u_{2}+\cdots+u_{n}\right)^{n}}\right]^{\frac{1}{n}}
$$

where $n \geq 2$ represents the number of systems and $u_{i} \geq 0$ represents the evaluation value of system $S_{i}(i=1,2, \cdots, n)$. It is easy to prove $C \in[0,1]$. The model (3) is zero order homogeneous and dimensionless. Before calculating the coupling coordination degree, the system values $u_{i}(i=1,2, \cdots, n)$ should be dimensionless, otherwise they cannot be added. In the index system of CHDI in this paper, $n=4$ (four core dimensions "life span, education, income and sustainability" are respectively represented by $S M, J Y, S R$ and $K C X)$. The coupling coordination degree of the four core dimensions of CHDI is as follows.

$$
C=4 \times\left[\frac{S M \cdot J Y \cdot S R \cdot K C X}{(S M+J Y+S R+K C X)^{4}}\right]^{\frac{1}{4}}
$$

\subsection{Exploratory Spatial Data Analysis}

Exploratory spatial data analysis (ESDA) is divided into global autocorrelation and local autocorrelation. The method is used to measure correlations between space units and to 
explore clustering and heterogeneity between space units. Its ultimate goal is to be able to grasp the mechanisms of spatial interaction between space units (Anselin et al. 1997). This method has been applied in many other aspects, such as population growth and mobility (Ye et al. 2011).

\subsubsection{Global Spatial Autocorrelation}

Global Moran's I statistic is a common indicator to judge whether the research objects have aggregation phenomenon in the whole research area (Getis et al. 1992). It reveals the average correlation degree of the research objects in the whole research area, but it cannot specifically indicate which areas have aggregation phenomenon. The global Moran's I index is calculated as follows.

$$
I=\frac{n \sum_{i=1}^{n} \sum_{j=1}^{n} w_{i j}\left(X_{i}-\bar{X}\right)\left(X_{j}-\bar{X}\right)}{S^{2} \sum_{i=1}^{n} \sum_{j=1}^{n} w_{i j}}(i \neq j)
$$

where $n$ is the number of spatial units (31 provinces). $X_{i}$ and $X_{j}$ are the CHDI values of provinces $i$ and $j$ respectively. $S^{2}=\frac{1}{n} \sum_{i=1}^{n}\left(X_{i}-\bar{X}\right){ }^{2} \cdot \bar{X}=\frac{1}{n} \sum_{i=1}^{n} X_{i} \cdot w_{i j}$ is the element of row $i$ and column $j$ in the spatial weight matrix $W=\left(\begin{array}{ccc}w_{11} & \cdots & w_{1 n} \\ \vdots & \ddots & \vdots \\ w_{n 1} & \cdots & w_{n n}\end{array}\right)$. It represents the spatial connection between province $i$ and province $j$. It can be proved that $I \in[-1,1]$. If $I$ is closer to 1 , it means that CHDI is more spatially aggregated and less spatially differentiated. If $I$ is closer to -1 , it means that CHDI is more spatially differentiated. If $I=0$, it means that CHDI is randomly distributed in space and has no spatial correlation. In empirical studies, the geographical distance between spatial units, economic distance and whether spatial units are geographically adjacent to each other are usually utilized way to define the spatial weight matrix. For example, the following spatial weight matrices are used.

3.3.1.1 (1) Geographic adjacency weights (W1) (Lesage 1999). When two provinces $i$ and $j$ are geospatially adjacent, define $w_{i j}=1 \mathrm{in} W$. When two provinces $i$ and $j$ are not adjacent, define $w_{i j}=0$ in $W$. i.e.

$$
w_{i j}=\left\{\begin{array}{l}
1, \text { wheni, jisadjacent } \\
0, \text { wheni, jisnotadjacent }
\end{array}\right.
$$

where $i, j=1,2, \cdots, 31$. It is usually specified that province $i$ is not adjacent to itself, i.e. $w_{i i}=0$. Since Hainan is not adjacent to any province, it is usually specified that Hainan is adjacent to Guangdong for the convenience of processing. The matrix formed by the $w_{i j}$ in (6) is called the geographic adjacency weight matrix. It is denoted as $W 1$.

3.3.1.2 (2) Geographical distance weights (W2) (Tiiu and Friso 2006). When the distance between the centers (capitals) of two provinces $i$ and $j$ is $d_{i j}$, define $w_{i j}=1 / d_{i j}$ in $W$. That is

$$
w_{i j}=\left\{\begin{array}{l}
1 / d_{i j}, i \neq j \\
0, i=j
\end{array}\right.
$$


The spatial weight matrix formed by $w_{i j}$ in Eq. (7) is called the geographic distance weight matrix. It is denoted as $W 2$.

3.3.1.3 (3) Economic distance weights (W3) (Tang, et al. 2014). Let $Y_{i t}$ be the GDP per capita of province $i$ in period $t, t \in[1, T]$ and $T$ be the number of periods in the study period, $\bar{Y}_{i}=\sqrt[(1+T) T]{\prod_{t=1}^{t=T} Y_{i t}^{2 t}},(i=1, \cdots, N)$. Define $w_{i j}$ in $W$ as

$$
w_{i j}=\left\{\begin{array}{l}
\frac{1}{\left|\bar{Y}_{i}-\bar{Y}_{j}\right|} \times \frac{\bar{Y}_{i}}{\sum_{n=1}^{n=N} \bar{Y}_{n}}, i \neq j \\
0, i=j
\end{array}\right.
$$

The weight matrix formed by $w_{i j}$ in Eq. (8) is called the economic distance weight matrix. It is denoted as $W 3$. The advantage of the spatial weight matrix is that the relatively developed provinces can produce more radiation and attraction to the "surrounding" provinces when defining the economic distance between the two provinces.

\subsubsection{4 (4) Weight of the combination of geographical and economic distances (W4) (Li, Tan} and Bai 2010). Set $W_{d}$ as the spatial weight matrix of geographic distances. Let $\bar{Y}_{i}=\frac{1}{\left(t_{1}-t_{0}+1\right)} \sum_{t=t_{0}}^{t=t_{1}} Y_{i t}$ be the average of the economic level (GDP per capita) of the $i$-th province in 1990-2017. $\bar{Y}=\frac{1}{\left(t_{1}-t_{0}+1\right)} \sum_{i=1}^{i=n} \sum_{t=t_{0}}^{t=t_{1}} Y_{i t}$ is the average of the economic level (GDP per capita) of the 31 provinces during the study period 1990-2017. $\operatorname{diag}\left(\frac{\bar{Y}_{1}}{\bar{Y}}, \frac{\bar{Y}_{2}}{\bar{Y}}, \cdots, \frac{\bar{Y}_{n}}{\bar{Y}}\right)$ denotes the diagonal matrix with $\frac{\bar{Y}_{1}}{\bar{Y}}, \frac{\bar{Y}_{2}}{\bar{Y}}, \cdots, \frac{\bar{Y}_{n}}{\bar{Y}}$ as the diagonal element. $t_{0}$ denotes the beginning of the study period and $t_{1}$ denotes the end of the study period. Define the combined spatial weight of geographic and economic distances as

$$
W_{4}=W_{d} \operatorname{diag}\left(\frac{\bar{Y}_{1}}{\bar{Y}}, \frac{\bar{Y}_{2}}{\bar{Y}}, \cdots, \frac{\bar{Y}_{n}}{\bar{Y}}\right)
$$

The spatial weight matrix in Eq. (9) shows that when a province's GDP per capita has a larger share of the average of the 31 provinces' GDP per capita, the greater its impact on neighboring provinces. That is, when $\frac{\bar{Y}_{i}}{\bar{Y}}>\frac{\bar{Y}_{j}}{\bar{Y}}$ there is $w_{i j}>w_{j i}$.

\subsubsection{Local Spatial Autocorrelation}

3.3.2.1 (1) Local Moran Index. To analyze the similarity or correlation of CHDI between each province and its neighbors, the LISA (Local Indicators of Spatial Association) analysis method is introduced in this paper. It can determine the degree of association of CHDI in local spatial regions. The test statistic is the following local Moran's I Index (notated as $I_{i}$ ) (Anselin 1995).

$$
I_{i}=\frac{n\left(X_{i}-\bar{X}\right) \sum_{j \neq i} w_{i j}\left(X_{j}-\bar{X}\right)}{\sum_{i}\left(X_{i}-\bar{X}\right)^{2}}=\frac{\left(X_{i}-\bar{X}\right) \sum_{j \neq i} w_{i j}\left(X_{j}-\bar{X}\right)}{S^{2}}=Z_{i} \sum_{j \neq i} w_{i j} Z_{j}
$$

where $Z_{i}=\frac{X_{i}-\bar{X}}{S}$ and $Z_{j}=\frac{X_{j}-\bar{X}}{S}$ are standardized observation values, $S^{2}=\frac{1}{n} \sum_{i=1}^{n}\left(X_{i}-\bar{X}\right)^{2}$. $w_{i j}$ is the same spatial weight as above. If $I_{i}>0$, it indicates a positive local spatial correlation, i.e., there is an aggregation effect of high CHDI values between province $i$ and 
neighboring provinces ("High-High" clustering), or there is an aggregation effect of low CHDI values ("Low-Low" clustering). If $I_{i}<0$, it indicates a negative local spatial correlation, i.e., there is a large difference in CHDI values between province $i$ and neighboring provinces ("High -Low" or "Low-High" clustering). If $I_{i}=0$, the local space is irrelevant.

3.3.2.2 (2) Spatial Regression Model. When the spatial autocorrelation exists in the CHDI of 31 provinces, the traditional econometric method to study the influencing factors of CHDI violates the hypothesis that the research units are independent. Therefore, the spatial effect of CHDI should be included in the econometric model and the spatial econometric model should be used. Elhorst (2003) extended the traditional econometric model to spatial econometric model by introducing spatial lag term based on traditional data model. According to the different spatial action mechanism, spatial autoregression (SAR) model of Eq. (11) and spatial error model (SEM) of Eq. (12) are commonly used in spatial panel data regression models (Han and Lee 2013; Lopez-Hernandez 2013).

$$
\begin{aligned}
& 1 n C H D I_{i t}=\alpha+\rho \sum_{i=1}^{n} w_{i j} 1 n C H D I_{i t}+\beta_{1}\left(1 \mathrm{n} G D P_{i t}\right)+\beta_{2}\left(1 n F E F_{i t}\right)+\beta_{3}\left(1 n U R_{i t}\right) \\
& +\beta_{4}\left(1 n F S S E_{i t}\right)+\beta_{5}\left(1 n C E_{i t}\right) \\
& +\beta_{6}\left(1 n F D I_{i t}\right)+\beta_{7}\left(1 n H P_{i t}\right)+\mu_{i}+\xi_{t}+\varepsilon_{i t}, \varepsilon_{i t} \sim N\left(0, \sigma_{\varepsilon}\right)
\end{aligned}
$$

$$
\begin{aligned}
& 1 n C H D I_{i t}=\alpha+\beta_{1}\left(1 n G D P_{i t}\right)+\beta_{2}\left(1 n F E F_{i t}\right)+\beta_{3}\left(1 n U R_{i t}\right)+\beta_{4}\left(1 n F S S E_{i t}\right)+\beta_{5}\left(1 n C E_{i t}\right) \\
& +\beta_{6}\left(1 n F D I_{i t}\right)+\beta_{7}\left(1 n H P_{i t}\right)+\mu_{i}+\xi_{t}+\varepsilon_{i t}, \varepsilon_{i t}=\lambda W \varepsilon_{i t}+u_{i t}, u_{i t} \sim N\left(0, \sigma_{u}\right)
\end{aligned}
$$

Among them, the explanatory variables include per capita gross domestic product $(G D P)$, per capita financial education funds $(F E F)$, urbanization rate $(U R)$, per capita fiscal social security and employment funds (FSSE), per capita carbon emissions $(C E)$, foreign direct investment intensity $(F D I)$ and the number of health professionals per 10,000 people $(H P) . w_{i j}$ is the element of row $i$ and column $j$ in the spatial weight matrix $W . \rho$ is the spatial autocorrelation coefficient, which reflects whether there is significant spatial correlation between different spatial units. That is, for a given definition of "spatial adjacency", the "average" external effects of other "adjacent" spatial units on this unit. $\lambda$ is the spatial error autocorrelation coefficient. $\beta_{k}(k=1,2, \cdots, 7)$ is the coefficient of explanatory variable. $\mu_{i}$ and $\xi_{t}$ represent optional spatial and temporal effects, respectively.

\section{Empirical Results}

\subsection{Spatiotemporal Evolution of CHDI}

\subsubsection{Spatiotemporal Evolution}

The CHDI values for the country and 31 provinces were measured for the period 1990-2017 using data for all indicators in Table 1 and the calculation procedures and formulas described earlier. The results of the calculations and their rankings are shown in Table 2 (only the data for three representative years are shown in Table 2; the complete data are shown in Table 7 in the Appendix). As shown in Table 2, China's CHDI 
Table 2 CHDI values and rankings for the country and 31 provinces

\begin{tabular}{|c|c|c|c|c|c|c|}
\hline Region & 2017 & Ranking (2017) & 2003 & Ranking (2003) & 1990 & Ranking (1990) \\
\hline National & 0.7898 & - & 0.7035 & - & 0.5943 & - \\
\hline Beijing & 0.8982 & 1 & 0.8245 & 1 & 0.7512 & 1 \\
\hline Shanghai & 0.8765 & 2 & 0.8196 & 2 & 0.7102 & 2 \\
\hline Tianjin & 0.8608 & 3 & 0.7793 & 3 & 0.6648 & 3 \\
\hline Zhejiang & 0.8385 & 4 & 0.7362 & 7 & 0.5668 & 14 \\
\hline Guangdong & 0.8284 & 5 & 0.7468 & 4 & 0.6640 & 4 \\
\hline Jiangsu & 0.8243 & 6 & 0.7396 & 5 & 0.6055 & 7 \\
\hline Fujian & 0.7990 & 7 & 0.7108 & 9 & 0.6004 & 10 \\
\hline Shandong & 0.7978 & 8 & 0.7147 & 8 & 0.5896 & 12 \\
\hline Liaoning & 0.7915 & 9 & 0.7396 & 6 & 0.6301 & 5 \\
\hline Hubei & 0.7825 & 10 & 0.6752 & 13 & 0.5999 & 11 \\
\hline Anhui & 0.7801 & 11 & 0.6349 & 24 & 0.4985 & 27 \\
\hline Hunan & 0.7795 & 12 & 0.6590 & 17 & 0.5049 & 23 \\
\hline Chongqing & 0.7787 & 13 & 0.6487 & 18 & 0.5012 & 24 \\
\hline Shaanxi & 0.7786 & 14 & 0.6853 & 12 & 0.5887 & 13 \\
\hline Jiangxi & 0.7760 & 15 & 0.6664 & 14 & 0.4994 & 26 \\
\hline Henan & 0.7715 & 16 & 0.6296 & 25 & 0.4955 & 28 \\
\hline Heilongjiang & 0.7676 & 17 & 0.6864 & 11 & 0.6040 & 8 \\
\hline Sichuan & 0.7626 & 18 & 0.6454 & 23 & 0.5147 & 20 \\
\hline Hebei & 0.7597 & 19 & 0.6651 & 15 & 0.5280 & 17 \\
\hline Hainan & 0.7571 & 20 & 0.6633 & 16 & 0.6020 & 9 \\
\hline Jilin & 0.7530 & 21 & 0.6965 & 10 & 0.6112 & 6 \\
\hline Shanxi & 0.7281 & 22 & 0.6455 & 22 & 0.5084 & 22 \\
\hline Ningxia & 0.7269 & 23 & 0.6466 & 21 & 0.5418 & 16 \\
\hline Inner Mongolia & 0.7260 & 24 & 0.6483 & 19 & 0.5454 & 15 \\
\hline Guangxi & 0.7173 & 25 & 0.6238 & 26 & 0.5095 & 21 \\
\hline Xinjiang & 0.7059 & 26 & 0.6185 & 27 & 0.5253 & 19 \\
\hline Yunnan & 0.6906 & 27 & 0.5860 & 29 & 0.4769 & 29 \\
\hline Guizhou & 0.6900 & 28 & 0.5766 & 30 & 0.4996 & 25 \\
\hline Gansu & 0.6638 & 29 & 0.6052 & 28 & 0.5256 & 18 \\
\hline Qinghai & 0.6377 & 30 & 0.6480 & 20 & 0.4603 & 30 \\
\hline Tibet & 0.6228 & 31 & 0.5237 & 31 & 0.4234 & 31 \\
\hline
\end{tabular}

for the three representative years 1990 (the beginning of the period), 2003 (the transition year of development level) and 2017 (the end of the period) are $0.5943,0.7035$ and 0.7898 , respectively. According to the classification standard of human development level by UNDP, China's human development level reached the medium level in 1990, increased to the high level in 2003 and approached the extremely high level in 2017. To analyze the spatiotemporal evolution characteristics of CHDI in China, ArcGIS10.2 software was used to visualize the CHDI values of 31 provinces in 1990, 2003 and 2017. As shown in Fig. 1.

From Fig. 1, it can be found that China's CHDI has the following spatio-temporal pattern evolution characteristics. 


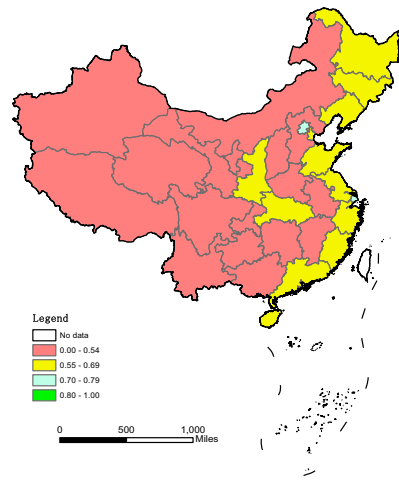

(a) 1990

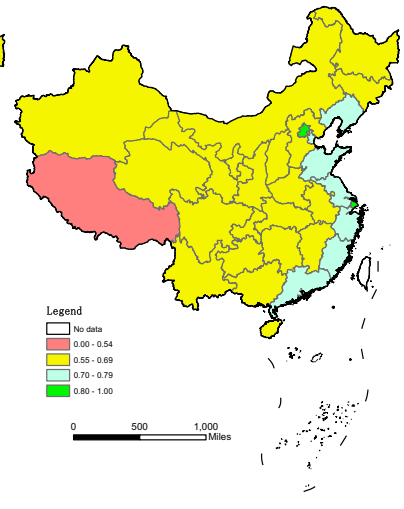

(b) 2003

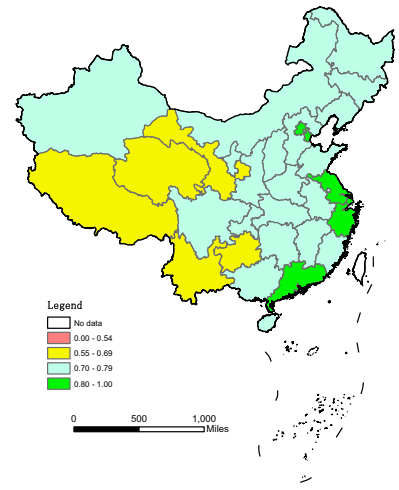

(c) 2017

Fig. 1 Temporal and spatial evolution of CHDI in 31 provinces of mainland China: 1990-2017

1. From 1990 to 2003 , most of the 31 provinces developed from the low level represented by red to the medium level represented by yellow. In 1990, 2 provinces (Beijing and Shanghai) were at a higher level of development, accounting for $6.45 \%$ of the 31 provinces; 12 provinces (Tianjin Guangdong, Liaoning, Zhejiang, Jilin, Jiangsu, Heilongjiang, Hainan, Fujian, Hubei, Shandong and Shaanxi) were at the medium level of development, accounting for $38.71 \%$ of the 31 provinces; the remaining 17 provinces were of low development level, accounting for $54.84 \%$ of the 31 provinces. In 2003, all the other 30 provinces rose to the medium level or above, except that Tibet remained at a low level of development. Among them, Beijing and Shanghai have reached a very high level of development. Tianjin, Guangdong, Liaoning, Jiangsu, Zhejiang, Shandong and Fujian have risen to a higher level of development. It can be found from Fig. 1 that there is a big gap between the development of CHDI in the central and western regions and the eastern coastal areas during 1990-2003.

2. From 2003 to 2017 , the human development level of 31 provinces was further improved. From the medium development level represented by yellow in most provinces, it has evolved into the higher development level represented by blue in most provinces. The average value of CHDI in 31 provinces increased from 0.6738 to 0.7636 , with an average annual growth rate of $0.90 \%$. From the East, central, Western and Northeast China, the average value of the eastern region increased from 0.7400 to 0.8240 , with an average annual growth rate of $0.77 \%$. The average value of the central region increased from 0.6518 to 0.7696 , with an average annual growth rate of $1.19 \%$. The average value of the western region increased from 0.6213 to 0.7084 , with an average annual growth rate of $0.94 \%$. The average value of Northeast China increased from 0.7075 to 0.7707 , with an average annual growth rate of $0.61 \%$. This is the smallest increase compared to the other regions. In 2017, Beijing, Tianjin, Shanghai, Jiangsu, Zhejiang and Guangdong in the eastern region have risen to a very high level of development. The average value of eastern China is 0.8240 , which is the first gradient of human development level in China. The average values of CHDI in Northeast, central and western regions were $0.7707,0.7696$ and 0.7084 , respectively, which belonged to the second, third and fourth gradients. It is worth noting that Yunnan, Guizhou, Gansu, Qinghai and Tibet in the 
western region are still at a medium level of development. Nationwide, the development gap between regions is narrowing.

3. According to the CHDI ranking of 31 provinces, Beijing, Shanghai and Tianjin have remained in the top three and the last three provinces have evolved from Yunnan, Qinghai and Tibet to Gansu, Qinghai and Tibet. Obviously, the 31 provinces with CHDI ranking at the front and rear ends show the characteristics of high spatial overlap between human development level and economic development level. Shanghai, Beijing and Tianjin, the provinces with higher CHDI, are also relatively in the lead in economic development. Tibet, Qinghai, Gansu and Yunnan, which are at the bottom of the list, are also relatively backward regions in economic development. It is worth mentioning that during the whole research period, the ranking of CHDI of the three provinces in Northeast China decreased significantly. The ranking of the three provinces of Liaoning, Jilin and Heilongjiang decreased from 5th, 6th and 8th in 1990 to 9th, 21st and 17th respectively in 2017. As the northeast region is a Traditional Resource-based Region, the region is in the key period of industrial restructuring and there is a lack of development power, which makes the level of human development relatively decline.

Overall, the level of human development in China has steadily increased over the 28 years from 1990 to 2017 and the CHDI values in the 31 provinces are both spatially correlated and divergent. The national average increased from 0.5596 in 1990 to 0.7636 in 2017 , with an average annual growth rate of $1.16 \%$. In 1992, the report of the 14th National Congress of the Communist Party of China proposed to accelerate the pace of economic construction and adjust the average annual growth rate of GDP from 6 to $8 \%-9 \%$. As a result, China's economy grew at a high speed from 1992 to 2002 and the income as the main driving force promoted the growth of the first stage of China's human development. Since 2002, China has put forward a series of major development strategies, such as building a well-off society in an all-round way, developing the western region, scientific development concept and development concept in the new period, which has promoted the second rapid growth and gathering period of China's human development from 2003 to 2017.

\subsubsection{Convergence Analysis}

From the analysis in Sect. 4.1.1, it can be seen that the levels of human development in the 31 provinces are both spatially correlated and differentiated at the same time. This section will analyze whether there is convergence in human development levels in the 31 provinces under the influence of such a spatial pattern, i.e., whether there is a catch-up effect of lagging provinces on developed provinces.

Convergence is usually divided into $\alpha$ convergence and $\beta$ convergence (Baumol 1986). The coefficient of variation is used to measure the dispersion of CHDI in 31 provinces in China to test whether there is $\alpha$ convergence. The measurement results (Fig. 2) show that the coefficient of variation showed a fluctuating downward trend from 1990-2017. This indicates the presence of $\alpha$ convergence in China's CHDI. The coefficient of variation can only reflect the stock change characteristics of CHDI. In order to further analyze the trend of the growth rate of human development in China's provinces and to test whether there is a catch-up effect of backward regions on developed regions, an incremental analysis from the perspective of $\beta$ convergence is needed. In this paper, the panel model shown in Eq. (13) is selected for $\beta$ convergence analysis. 


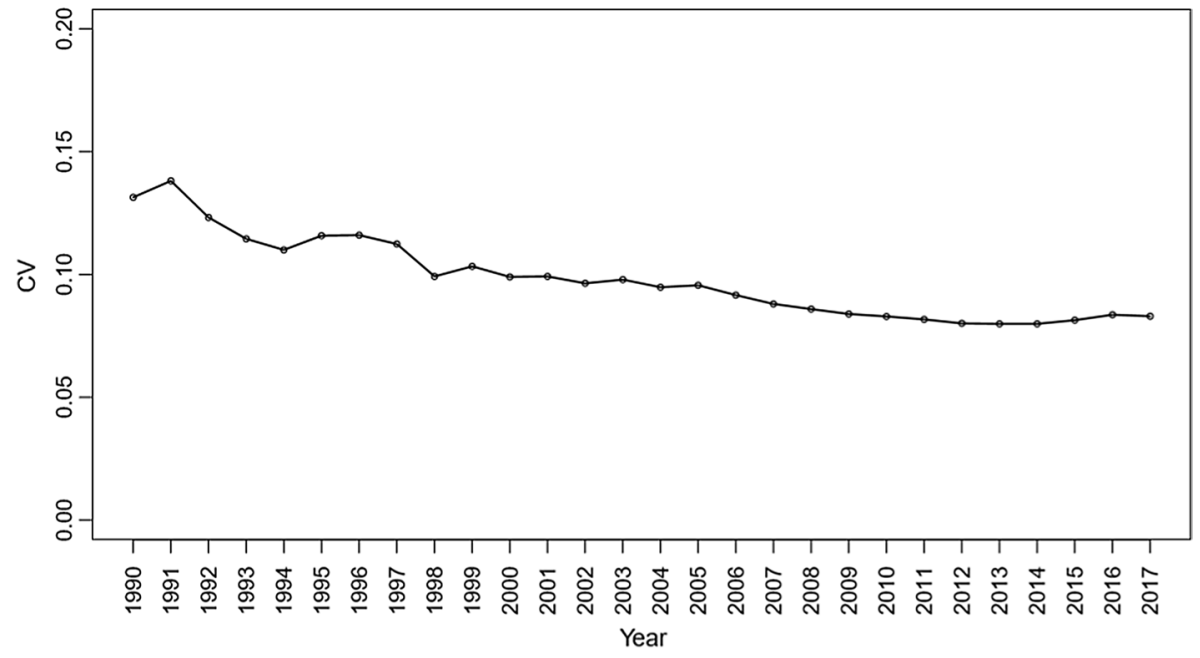

Fig. 2 Coefficient of variation of CHDI in 31 provinces: 1990-2017

$$
\frac{1}{T} \ln \left(\frac{C H D I_{i, t_{0}+T}}{C H D I_{i, t_{0}}}\right)=\alpha_{0}+\beta \ln \left(C H D I_{i, t_{0}}\right)+\mu_{i}+\varepsilon_{i, t_{0}+T}
$$

where $i(i=1,2, \cdots, 31)$ denotes the province, $T(T=1,2, \cdots, 28-1)$ denotes the length of the study period, the dependent variable $\frac{1}{T} \ln \left(\frac{C^{C H D I_{i, t_{0}+T}}}{C H D I_{i, t_{0}}}\right)$ is the growth rate of CHDI, the independent variable $\ln \left(C H D I_{i, t_{0}}\right)$ is the initial level, $\mu_{i}$ is the individual fixed effect and $\varepsilon_{i, t_{0}+T}$ is the residual term.

Using the LLC method in the unit root test, the results of the unit root test for the two variables $\frac{1}{T} \ln \left(\frac{C H D I_{i, t_{0}+T}}{C H D I_{i, t_{0}}}\right)$ and $\ln \left(C H D I_{i, t_{0}}\right)$ show that they are both smooth. Because the study was conducted on specific individuals (31 provinces in China) and the random effects assumption was too strong for convergence analysis, the fixed-effects model was chosen between fixed and random effects in the regression analysis. The regression results of the model show that the coefficient $\beta=-0.0131$ and is significant at the $1 \%$ significance level. The value of coefficient $\beta$ is negative, which indicates that there is absolute $\beta$ convergence of CHDI in China's provinces and the convergence rate is $1.31 \%$ per year. That is, lagging regions have a slow catch-up effect on developed regions. This confirms the previous conclusion that the regional disparities in China's human development are gradually narrowing.

\subsection{Spatial Autocorrelation}

Based on the analysis of the spatiotemporal evolution of the CHDI in the previous section, it can be intuitively found that China's CHDI is spatially correlated. This section uses the Moran index to further test the spatial correlation of China's CHDI. Because different spatial weight matrices may produce different degrees of spatial correlation for spatial units, the proper selection of spatial weight matrices is crucial for the spatial correlation analysis of CHDI. The spatial correlation of the CHDI is first tested based on the four spatial 
weights in Sect. 3.3.1. Then the optimal spatial weight matrix is selected according to the method of Stakhovych et al. (2009). The regression results under optimal spatial weights are used as a basis for analyzing the mechanism of CHDI in China.

\subsubsection{Global Spatial Autocorrelation}

Global spatial autocorrelation describes the overall spatial relationship of all units within the study space. The commonly used test statistic is the global Moran index. The global Moran index for the CHDI was calculated for the 31 provinces based on the four spatial weights in Sect. 3.3.1. The results are shown in Table 3. The results show that the global Moran's I values are positive under all four spatial weights within the period 1990-2017. Among them, these global Moran's I values under the geographic adjacency spatial weight $W 1$ are within [0.3732, 0.5551]. These global Moran's I values under the geographic distance spatial weight $W 2$ are within [0.0809, 0.1501]. These global Moran's I values under the economic distance spatial weight $W 3$ are within [0.3854, 0.5350]. These global Moran's I values under the spatial weight $W 4$ for the combination of geographic distance and economic distance are within $[0.1162,0.1501]$. Thus, on the national average, the CHDI has a significant spatial aggregation effect under all four spatial weights.

\subsubsection{Local Spatial Autocorrelation}

Typically, there will be spatial differences in the level of spatial autocorrelation. Since global indicators cannot portray the spatial variability of spatial autocorrelation, local indicators are needed to detect local spatial autocorrelation. This section uses ESDA analysis method to further analyze the local spatial correlation of CHDI in 31 provinces. According to the regression results in Sect. 4.2.3,W3 is the optimal spatial weight. Therefore, the local spatial correlation of CHDI in the 31 provinces should be analyzed based on the spatial weight $W 3$. Using ArcGIS10.2 software, the LISA significance maps of CHDI of 31 provinces in 1990, 2003 and 2017 were drawn $(\mathrm{P}=0.05)$. The results are shown in Fig. 3. "High-High cluster" means that the CHDI value of the province and "neighboring" provinces are high and the spatial difference is not significant. "Low-Low cluster" means that the CHDI values of this province and "neighboring" provinces are low and the spatial difference is not significant. "High-Low outlier" means that the CHDI value of the province is higher, while that of the "neighboring" provinces is low and the spatial difference is large. "Low-High outlier" means that the CHDI value of the province is low, while that of the "neighboring" provinces is higher, with large spatial differences.

From Fig. 3, it can be found that CHDI of 31 provinces is positively correlated in space and polarization is obvious. In 1990, 2003 and 2017, the "Low-Low" aggregation pattern was mainly distributed in Tibet, Xinjiang, Qinghai, Yunnan and Gansu in the western region, while the "High -High" aggregation type was distributed in the "Beijing-Tianjin" region and Shanghai, Jiangsu and Zhejiang in the "Yangtze River Delta" region. During the whole study period from 1990 to 2017, "High-Low" and "Low-High" aggregation types were not statistically significant.

On the whole, the spatial differences of CHDI in China are mainly caused by the "HighHigh" and "Low-Low" agglomeration effects, while the "High-Low" and "Low-High" agglomeration effects are not obvious. As time goes on, "Low-Low" and "High-High" accumulation areas tend to expand. 


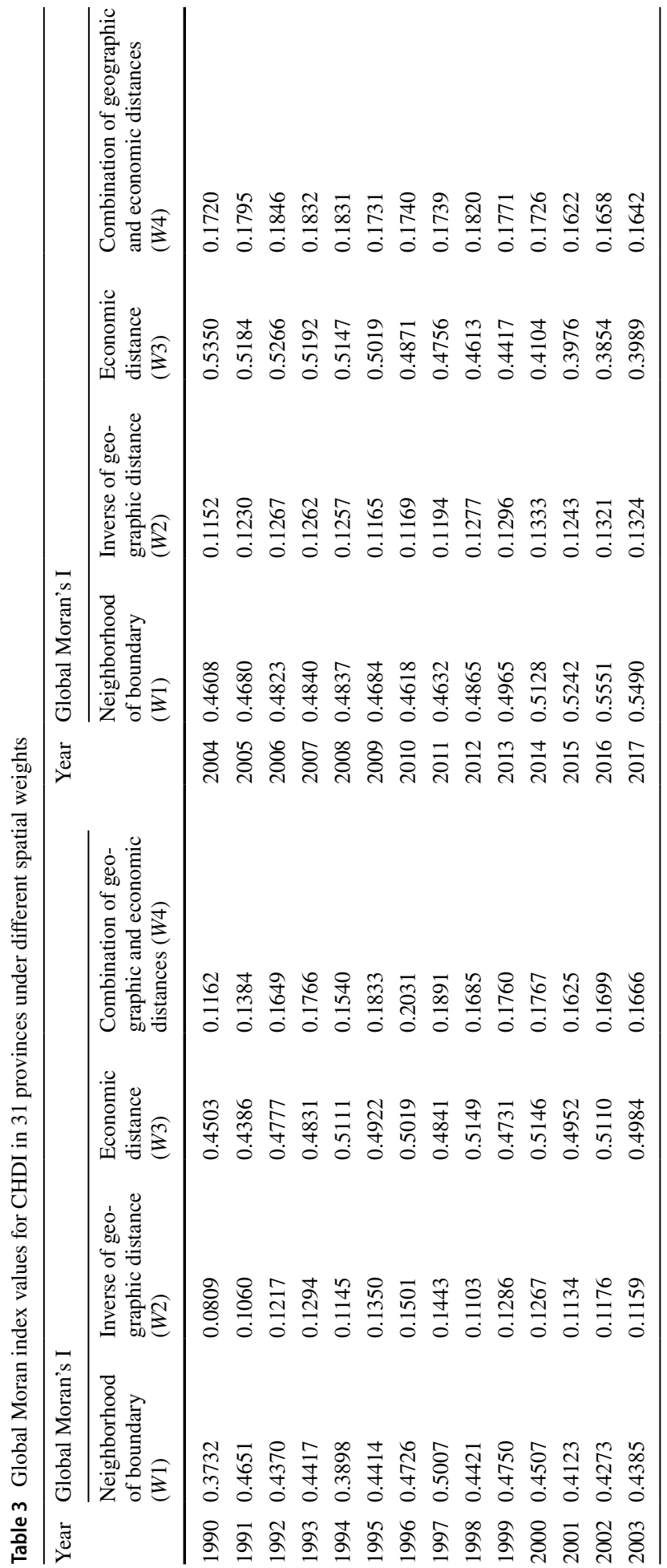




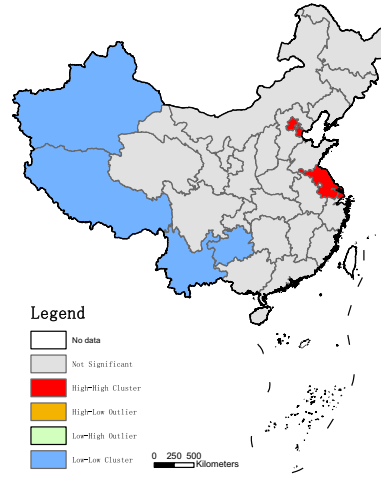

(a) 1990

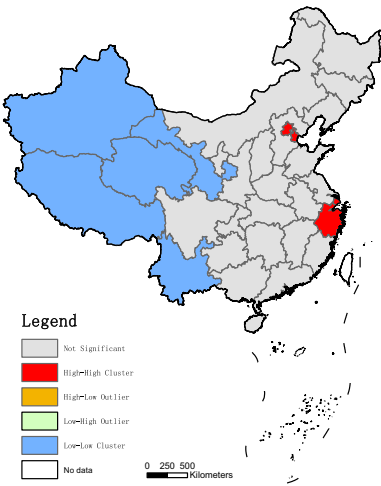

(b) 2003

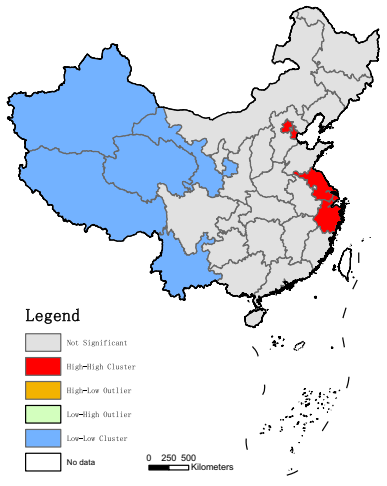

(c) 2017

Fig. 3 LISA significance map for CHDI in 31 provinces: 1990-2017

\subsubsection{Spatial Regression of CHDI}

Results may deviate from the true value when using traditional measurement models to analyze study units with spatial correlation. Spatial statistics and spatial econometric model study how to integrate spatial interaction and spatial structure into regression analysis, which can better describe the objective reality. To further analyze the influencing factors of CHDI in China, this paper selects the following seven explanatory variables to the dependent variable CHDI spatial regression.

1. GDP per capita. The most direct impact of economic growth is the improvement of people's living standards. With the increase of income level, residents will be able to enjoy better living environment, better medical and health conditions, more front-end education and provide financial guarantee for scientific and technological innovation and shared development achievements. Therefore, economic development can directly contribute to the level of human development.

2. Per capita financial education funds (FEF). The education expenditure of government finance directly affects the education index of human development. Education is a public utility, which mainly depends on the government's strong support. The government should take responsibility for education. Education is also an important aspect of people's livelihood development. Therefore, the expenditure of education funds directly affects the level of human development in a country or region.

3. Urbanization rate (UR). Urbanization rate refers to the proportion of urban permanent population in the total resident population of a region. Urban residents are far more than rural residents in terms of economic income, access to education and medical security. Thus, if the rate of urbanization in a region is higher, the more developed the economy and the higher the level of human development in that region.

4. Per capita financial social security and employment funds (FSSE). Social security and employment expenditure are the government's expenditure on social security and employment, which is an important means for the government to promote the development of people's livelihood and a direct embodiment of sharing the fruits of social development. 
5. Carbon emissions per capita (CE). A large amount of carbon dioxide emission is the main cause of greenhouse effect. Reducing carbon emissions is the direct embodiment of the concept of green development, which is of great significance to improve the sustainable development ability of a region.

6. Foreign direct investment intensity (FDI). Foreign direct investment in a region can promote local technological progress, international exchange and cooperation. It can reflect the openness of a region and help the sustainable development of the economy and society in the region.

7. The number of health professionals per 10,000 people (HP). Health professionals have a direct impact on the ability of medical and health services in a region. Therefore, it has an important impact on life span index and sustainable development index.

Before spatial regression, it is necessary to test the types of spatial correlation. Anselin and Rey (1991) based on many Monte Carlo simulation experiments, found that the Lagrange multiplier test of OLS regression can determine which one of SAR model and SEM model is better. The commonly used statistics are LM-lag, LM-err, robust LM-lag and robust LM-err (Elhorst 2005).

Based on the panel data of 31 provinces from 1990 to 2014, this paper uses MATLAB 2014b software to test the different spatial correlation types of CHDI based on four different spatial weights. The results are shown in Table 4. Firstly, LM-lag and robust LMlag were significant at $1 \%$ significance level under four different spatial weights. Secondly, LM-err and robust LM-err based on spatial weight $W 1$ were not significant at 5\% significance level. Robust LM-err based on spatial weights $W 2$ and $W 4$ was not significant at the 5\% significance level. In general, LM-lag and robust LM-lag are more significant than LM-err and robust LM-err. Therefore, it can be determined that the spatial autoregressive (SAR) model is superior to the spatial error model (SEM).

Table 4 Spatial autocorrelation test results for CHDI in China

\begin{tabular}{|c|c|c|c|}
\hline Types of spatial weights & Test method & Statistical value & P-value \\
\hline \multirow{4}{*}{$\begin{array}{l}\text { Rook contiguity } \\
(W 1)\end{array}$} & LM-lag & 19.1740 & 0.0000 \\
\hline & LM-err & 3.6528 & 0.0560 \\
\hline & Robust LM-lag & 15.5473 & 0.0001 \\
\hline & Robust LM-err & 0.0261 & 0.8717 \\
\hline \multirow{4}{*}{$\begin{array}{l}\text { Geographical distance } \\
(W 2)\end{array}$} & LM-lag & 92.7035 & 0.0000 \\
\hline & LM-err & 9.6178 & 0.0019 \\
\hline & Robust LM-lag & 83.0925 & 0.0000 \\
\hline & Robust LM-err & 0.0068 & 0.9345 \\
\hline \multirow{4}{*}{$\begin{array}{l}\text { Economic distance } \\
(W 3)\end{array}$} & LM-lag & 160.5665 & 0.0000 \\
\hline & LM-err & 6.7303 & 0.0095 \\
\hline & Robust LM-lag & 185.8419 & 0.0000 \\
\hline & Robust LM-err & 32.0057 & 0.0000 \\
\hline \multirow{4}{*}{$\begin{array}{l}\text { Combination of economic distance and } \\
\text { economic distance } \\
(W 4)\end{array}$} & LM-lag & 30.6488 & 0.0000 \\
\hline & LM-err & 7.2243 & 0.0072 \\
\hline & Robust LM-lag & 24.2145 & 0.0000 \\
\hline & Robust LM-err & 0.7901 & 0.3741 \\
\hline
\end{tabular}


The SAR model in Eq. (11) was used to regress the Chinese CHDI based on four spatial weight matrices. We also regressed the Chinese CHDI based on the general panel model (14) proposed by Ren et al. (2020) in order to facilitate comparison with previous models in the literature.

$$
C H D I_{i t}=\alpha_{0}+\beta_{1} \ln \left(G D P_{i t}\right)+\beta_{2} \ln \left(F E F_{i t}\right)+\beta_{3} \ln \left(U R_{i t}\right)+\beta_{4} \ln \left(F S S E_{i t}\right)+\beta_{5} \ln \left(M E_{i t}\right)+\varepsilon_{i t}
$$

The four variables, GDP, FEF, UR and FSSE, have the same meaning as the variables in the previous model (11). $M E$ denotes financial medical expenditure per capita. The estimation results of the above models are shown in Table 5.

It can be seen from Table 5 that among the regression results of SAR model under four spatial weights, the SAR model with spatial and temporal double fixed effects has the largest value of $\log$ likelihood function and the highest goodness-of-fit $R^{2}$. Among the regression results of SAR model with time and space double fixed effect, the log likelihood function value of regression result under economic distance weight $W 3$ is the largest. Stakhovych et al. (2009) pointed out that the spatial weight corresponding to the maximum value of $\log$ likelihood function should be selected in spatial regression. Therefore, $W 3$ is the optimal spatial weight in this paper. In addition, the log-likelihood function value and the goodness-of-fit $R^{2}$ are higher for the SAR spatiotemporal double-fixed model under the economic distance weight $W 3$ compared to the regression results of the model (14) proposed by Ren et al. (2020). Also, the coefficient of financial education funds $(F E F)$ is negative in the regression results of model (14), which is not as expected. Therefore, the SAR model with double fixed effects is superior to the other models in terms of model regression results.

Further, we test the performance of the models by comparing their prediction accuracy. First, the CHDI values for 31 provinces from 2015-2017 are predicted based on the regression results of the SAR model (a double fixed effects model based on the weight W3) and the model (14) proposed by Ren et al. (2020), respectively. Then, the prediction accuracy of each model is calculated by the formula $1-\frac{1}{n} \sum_{i=1}^{n}\left|\left(y_{i}-\hat{y}_{i}\right) / y_{i}\right|(n=31)$. Finally, Spearman's rank correlation coefficients between the predictions of each model and the CHDI values measured in this paper were calculated. The results are shown in Table 6. The results in Table 6 show that the prediction accuracy of the 2015-2017 SAR model is all higher than the prediction accuracy of the ordinary panel model (14) proposed by Ren et al. (2020). In addition, the Spearman rank correlation coefficients between the predicted values of the SAR model and the CHDI values are all higher than the Spearman rank correlation coefficients between the predicted values of the model (14) and the CHDI values. Therefore, the double fixed-effects SAR panel model in this paper is superior to the traditional panel model in the literature Ren et al. (2020) in terms of prediction results.

In summary, this paper should choose the regression results of the SAR model with spatial and temporal double fixed effects of the economic distance weighting matrix $W 3$ to analyze the influences of CHDI in China.

In Table 5, the SAR model estimation results of spatial-temporal double fixed effect under economic distance weight $W 3$ show that the estimated value of spatial autoregressive coefficient $\rho$ is 0.2848 , which is significant at the significance level of $1 \%$. This shows that China's CHDI has a strong spatial spillover effect between neighboring provinces. In other words, the CHDI of a province depends not only on its own factors, but also on the CHDI of its "neighboring" provinces. Specifically, given the spatial weight of economic distance $W 3$ and other conditions unchanged, the CHDI value of 


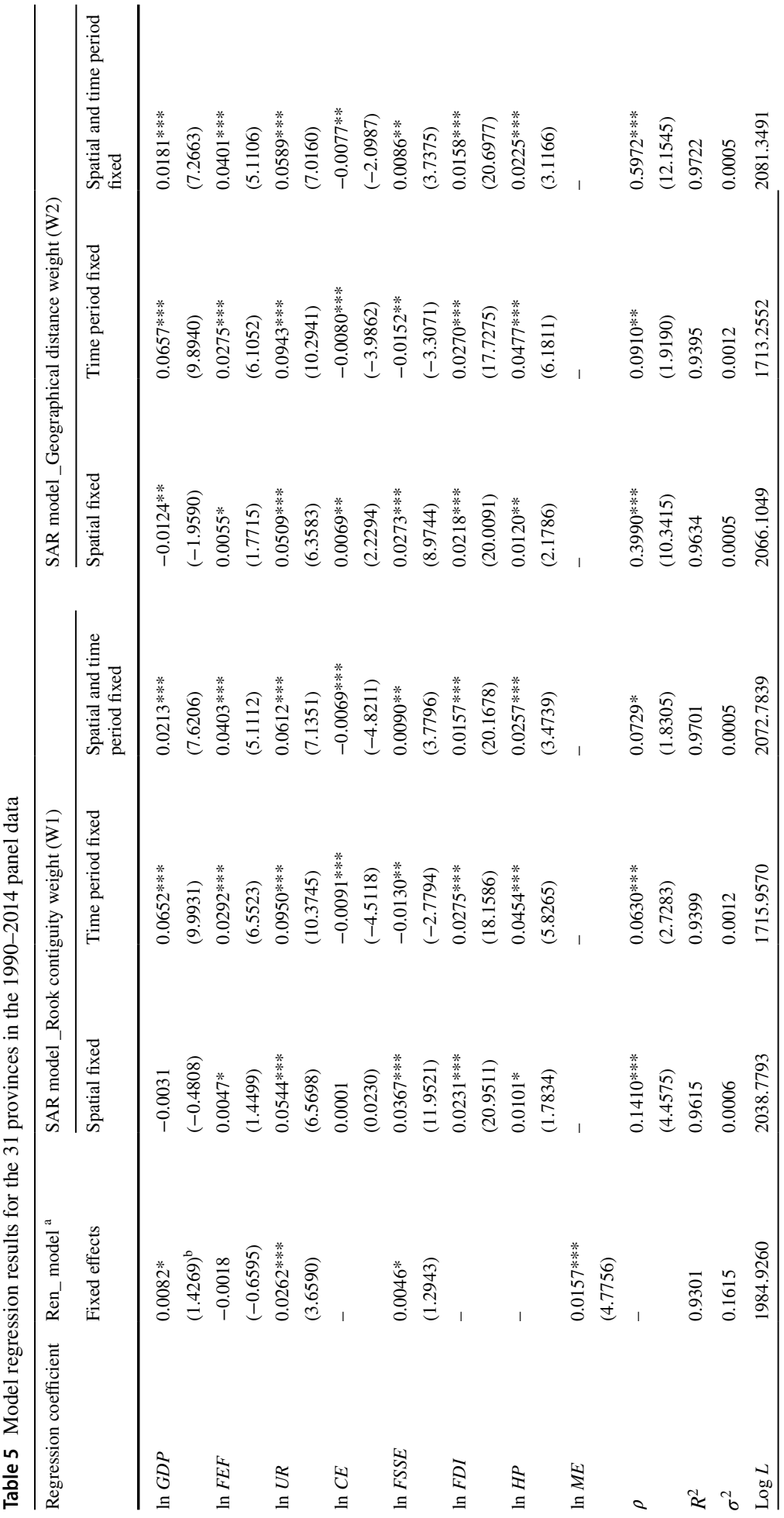




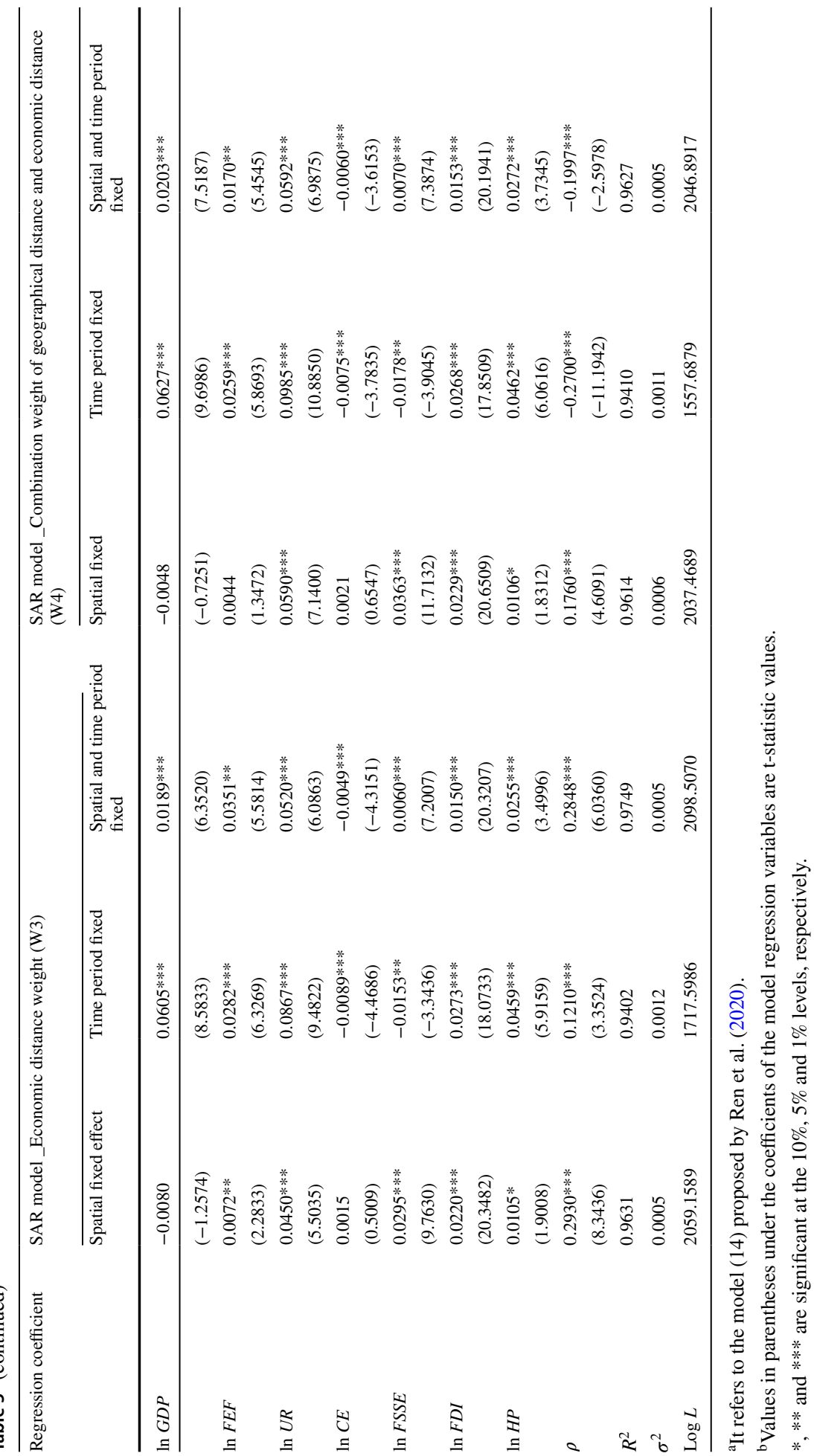


"neighboring" provinces increased by $1 \%$ may increase the average CHDI of this province by $0.2848 \%$. The CHDI of "neighboring" provinces has a significant positive effect on the CHDI of the province. As shown in Fig. 3 of Sect. 4.2.2, the "Beijing Tianjin" region and the "Yangtze River Delta" region with similar economic development level present the "High-High" clustering pattern of CHDI value. The western provinces of Tibet, Gansu, Qinghai, Xinjiang and Yunnan, which are also low in economic development, present a "Low-Low" aggregation pattern of CHDI values. This is consistent with the previous conclusion that China's CHDI has spatial spillover effect. Therefore, each province should actively strengthen its cooperation with provinces with higher levels of human development, thereby enhancing the level of human development in that province and in the "neighboring" provinces.

According to the coefficient of explanatory variables, all of them are significant at $5 \%$ significance level.

1. The elasticity coefficient of GDP per capita is 0.0189. It shows that the CHDI will increase by $0.0189 \%$ for every $1 \%$ increase of GDP per capita. By comparing the per capita GDP, economic growth rate and CHDI growth rate of 31 provinces in 2017, it is found that the economic growth of most provinces will promote the improvement of CHDI, which is the same as the result of full sample spatial econometric estimation. However, in some provinces with low economic development level, such as Gansu, Qinghai, Guangxi and Shanxi, economic growth will inhibit the increase of CHDI. This means that the economic growth in these provinces is still in the extensive mode and the resource and environmental costs of economic development are too high. It is an important task for these provinces to change the mode of economic development. Therefore, the conclusion that economic development can contribute to the increase of CHDI in the regression results of the SAR model is not absolutely valid. It can only show that economic growth can promote the level of human development in the whole country at this stage.

2. The elasticity coefficient of per capita financial education funds (FEF) is 0.0351 . It shows that under the same other conditions, the CHDI will increase by $0.0351 \%$ when the per capita financial education funds increase by $1 \%$. By comparing the per capita financial education expenditure, the growth rate of per capita financial education expenditure and the growth rate of CHDI in provinces of China in 2017, it is found that the education level of Tibet, Qinghai, Ningxia and Guizhou is relatively low and the financial expenditure on education is insufficient, which makes the growth of per capita financial education funds in these provinces play a very significant role in the improvement of CHDI. Beijing, Shanghai, Tianjin and Zhejiang provinces, which have higher per capita financial expenditure on education, have no obvious effect on CHDI. However, from the national level, the per capita financial expenditure on education is an important driving factor of China's CHDI. Therefore, we should gradually increase the proportion of financial expenditure on education funds to promote the further improvement of China's CHDI.

3. The elasticity coefficient of the urbanization rate (UR) is 0.0520 , which is the maximum value of the elasticity coefficient for all explanatory variables. This means that a $1 \%$ increase in the urbanization rate will raise the CHDI by $0.0520 \%$, other things being equal. Comparing the urbanization rate and CHDI value of 31 provinces in 2017, the top three provinces of urbanization rate, Shanghai, Beijing and Tianjin, are consistent with their CHDI values and there are similar situations between urbanization rates 


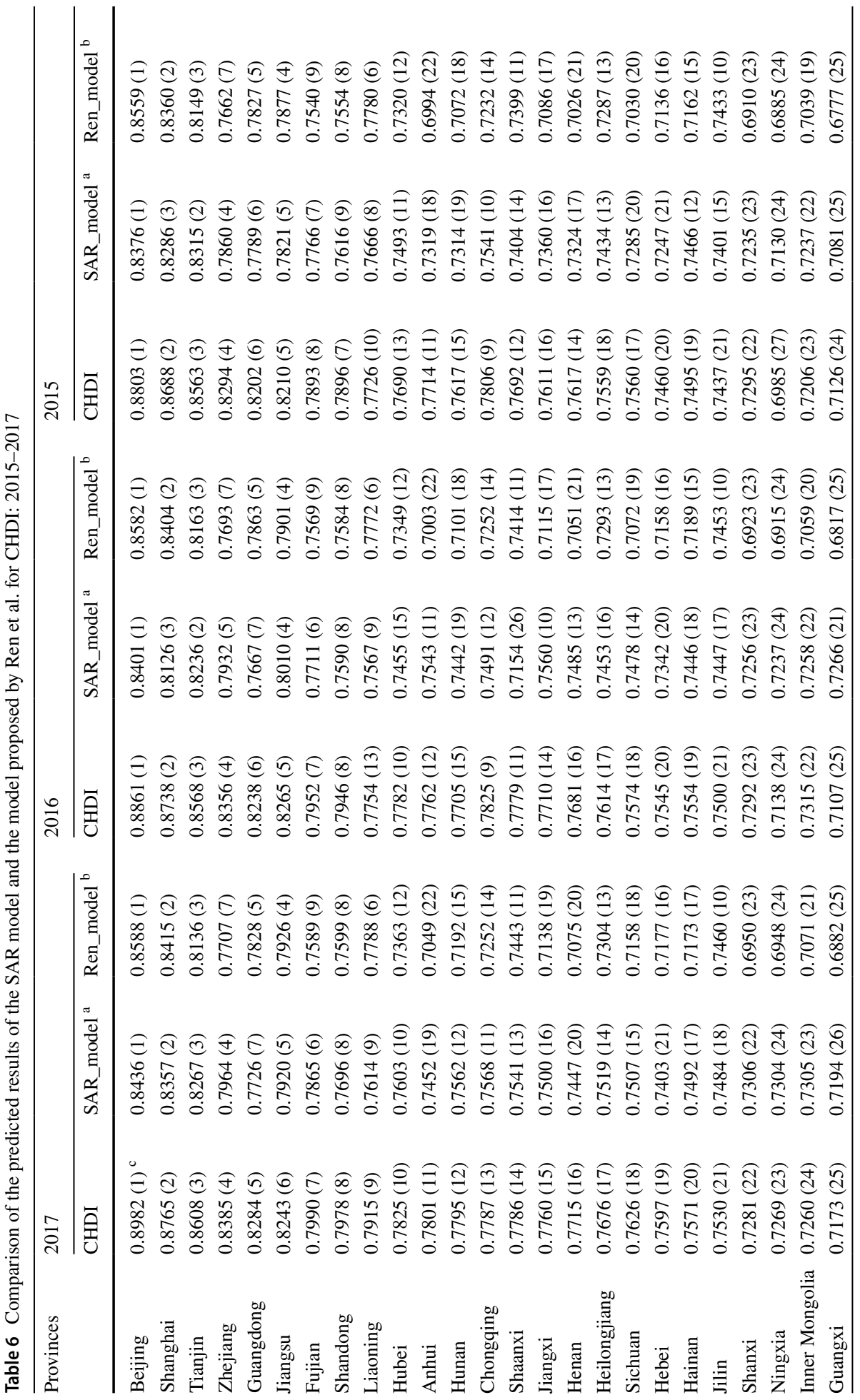




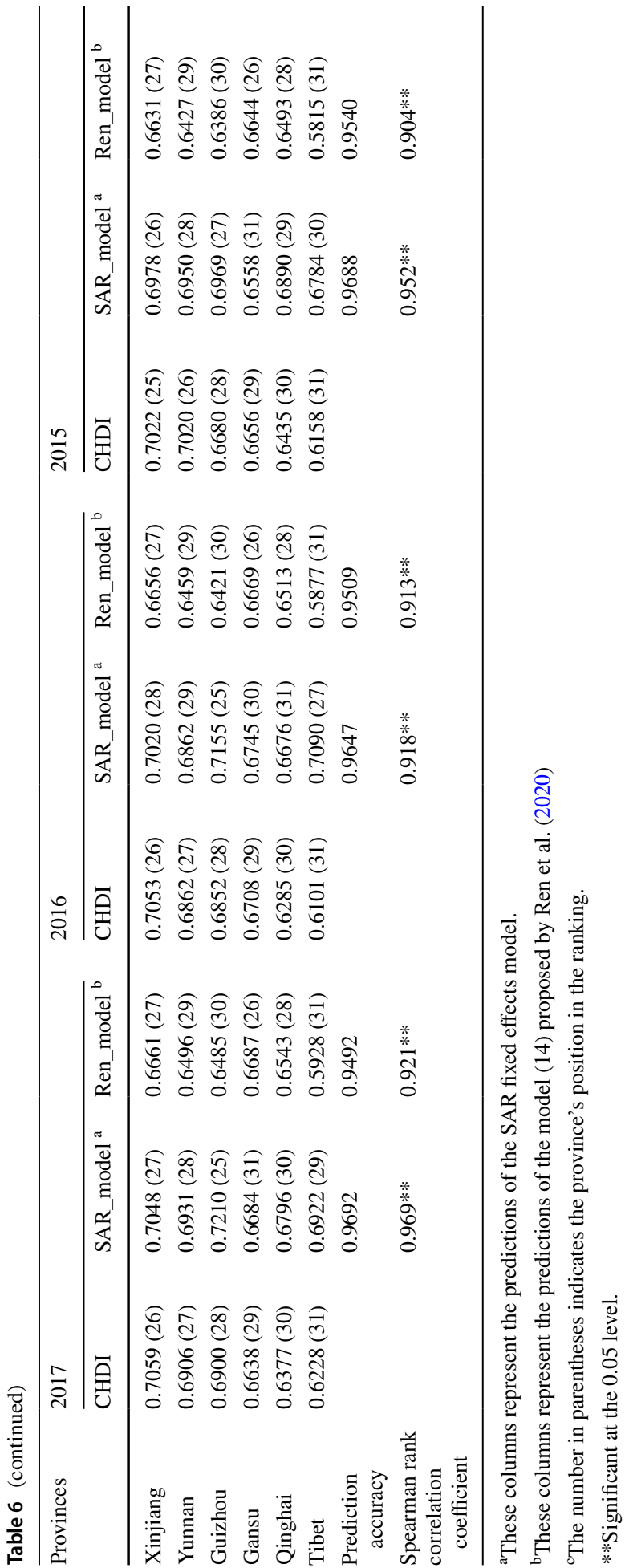


and CHDI values in other provinces. It shows that the urbanization rate is the most important influencing factor of CHDI in all provinces of China. As urban residents are far more than rural residents in terms of economic income, access to education and medical security, the level of urbanization has a direct impact on CHDI. The higher the urbanization rate, the higher the level of human development. Therefore, increasing the rate of urbanization or giving urban treatment to rural residents working in cities is an important means of increasing CHDI in China.

4. The elasticity coefficient of per capita carbon emission (CE) is -0.0049 . This means that a $1 \%$ decrease in per capita carbon emissions would increase CHDI by $0.0049 \%$, other things being equal. With the rapid development of China's economy, energy consumption is gradually increasing and the related carbon dioxide emissions are also increasing. The increase of energy consumption has brought great pressure to the environment. A lot of greenhouse gases are emitted into the environment, which is bound to cause chain reaction. In recent years, the Chinese government has issued a series of relevant measures and policies on carbon dioxide emissions. In order to ensure the realization of the 13th five-year plan carbon intensity reduction target, the completion of the carbon dioxide emission intensity reduction index is included in the comprehensive evaluation system of economic and social development of each region (or industry). These measures have an obvious effect on reducing China's per capita carbon emissions. In 2017, except for Inner Mongolia, Qinghai, Guangxi, Tibet and Shandong, the growth rate of per capita carbon emissions in the remaining 26 provinces was negative. At the national level, China's per capita carbon emissions continue to decline, which has become another driving factor of China's human development level.

5. The elasticity coefficient of per capita financial social security and employment funds (FSSE) is 0.0060 . This means that, other things being equal, a $1 \%$ increase in per capita FSSE expenditure would lead to a $0.0060 \%$ increase in the CHDI. Compared with other driving factors, the driving force is minimal. Social security is a basic socio-economic system in modern countries, an important guarantee of social stability and an important symbol of social progress. China's social security system started late and there are still some problems that need to be solved (Li 2020). Firstly, compared with developed countries, China's capital investment in social security is far from enough. It is necessary to increase the capital investment in social security and raise the proportion of social security expenditure. Secondly, the legislation of China's social security system lags and the legal guarantee is not sound. It is necessary to strengthen the legal system and raise the level of legislation. Third, the development of social security in China is unbalanced between urban and rural areas, with rural areas obviously lagging. It is necessary to coordinate urban and rural development and strengthen the construction of the rural social security system. Fourth, the operational efficiency of social security funds is low. There is a need to improve the efficiency of the operation of social security by broadening its sources of financing and investment. Through the above ways, China's social security system will be further improved. Thus, this will make the FSSE more effective in promoting the development of CHDI in China.

6. The coefficient of elasticity of the intensity of foreign direct investment (FDI) is 0.0150. It means that, all other conditions remaining unchanged, when the intensity of FDI increases by $1 \%$, the CHDI will increase by $0.0150 \%$. At the beginning of the reform and 
opening up, in order to solve the problem of capital shortage, the Chinese government lowered the environmental control standards when introducing foreign investment. The introduction of foreign investment has had a negative impact on China's ecology (List et al. 2000; Chen 2008). With the rapid economic development, the problem of environmental pollution has come to the fore. China's environmental control standards have gradually improved and the negative effects of foreign investment on the environment have gradually decreased. At present, foreign direct investment is not only conducive to higher income levels, but also brings advanced production equipment and technology levels. This has an important role to play in China's sustainable development.

7. The elasticity coefficient of health professionals (HP) per 10,000 people is 0.0255 . It shows that CHDI will increase by $0.0255 \%$ when the number of HP per 10,000 people increases by $1 \%$. The number of HP has a significant role in promoting CHDI in China. The number of health professionals in a region has a direct impact on the ability of medical services in the region and plays a very important role in the prevention of epidemics. Comparing the proportion of health professionals between urban and rural areas in China, it is found that the gap is very large and the number of rural health professionals is seriously insufficient. In order to effectively improve the capacity of China's health services, emphasis should be placed on increasing the proportion of health professionals in rural areas.

\section{Conclusions and Policy Recommendations}

Since 1990, China has made great achievements in economy and society and the level of human development has leaped from medium level to high level. In the process of development, there are also some problems such as the gap of development level between regions is too large and the development is not balanced and sufficient. The Chinese government has put forward five new development concepts to address these new issues in development. In order to adapt to the requirements of the new development concept to measure the level of human development in China, this paper first builds the sustainable development dimension of human development based on the five development concepts of "innovation, coordination, green, openness and sharing" and then builds the index system of China's human development index (CHDI) based on the four core dimensions of "life span, education, income and sustainable development". Using the index system and calculation method of this paper, the CHDI values of China and 31 provinces are measured and the spatiotemporal evolution and convergence of China's CHDI are analyzed. Then, the influences of CHDI in China were analyzed using ESDA method and spatial panel regression model. The following new findings were obtained: (1) CHDI in China has a significant spatial aggregation effect. In the western region, Tibet, Qinghai, Xinjiang, Gansu, Yunnan and Guizhou provinces have significant "Low-Low" clustering phenomenon, while "Beijing 
Tianjin" region and "Shanghai, Zhejiang, Jiangsu" Yangtze River Delta region have significant "High-High" clustering phenomenon. The development level of the eastern region is significantly higher than that of other regions. In addition, the CHDI has $\beta$ convergence in 31 provinces from 1990-2017, i.e., lagging provinces have a catch-up effect on developed provinces. (2) From the results of spatial correlation tests and spatial regressions, it can be seen that the CHDI values of the 31 provinces interact with each other spatially. A $1 \%$ increase in the CHDI of "neighboring" provinces of a province may increase the CHDI value of that province by $0.2848 \%$. (3) According to the explanatory variables of spatial panel regression, urbanization rate, per capita financial education funds and health professionals per 10,000 people are the main positive driving factors of CHDI in China and the per capita carbon emission is the main negative driving factor. According to the above conclusions, this paper get the following policy implications.

1. The Chinese government should accelerate the coordinated development of the eastern region with other regions. In the new period, the Chinese government has issued a new mechanism of regional coordinated development strategy, which puts forward new requirements for narrowing the regional development gap in China. In the future, promoting regional coordination of human development level should become the new focus of implementing China's regional coordinated development strategy and reducing regional differences in human development level and human well-being should be the priority. At the same time, based on narrowing the development gap between the East, the middle, the West and the northeast, we should continue to expand the leading role of regional growth poles in the "Yangtze River Delta", "Beijing Tianjin", "Sichuan, Chongqing, Shaanxi and Hubei", to realize the coordinated development between the region and its surrounding provinces.

2. A province's CHDI depends not only on its own influencing factors, but also on its neighboring provinces' CHDI. Interprovincial and regional cooperation should therefore be further strengthened. With the rapid development of China's economy and society, there are some pressures, such as shortage of resources and energy, deterioration of ecological environment and rising development costs. We should jump out of the province and seek close cooperation with other provinces, make full use of the resource's advantages of each province, jointly control environmental pollution, ecological protection and share scientific and technological innovation achievements. It presents a multichannel, multi field, diversified and all-round development trend. Finally, the common development and progress of human well-being in the whole country and all regions will be realized.

3. We should focus on improving the urbanization rate, per capita financial education funds and the number of health professionals per 10,000 people, which are the main 
driving factors of human development. At the same time, we should also accelerate the implementation of green development strategies to reduce per capita carbon emissions. First, the urbanization rate is the first driving force affecting China's CHDI. Therefore, to further improve the urbanization rate and give urban residents the same treatment to rural household registration personnel living in cities and towns is an important way to improve China's CHDI. Secondly, the government's expenditure on education is the second major factor affecting China's CHDI. We should gradually increase the proportion of financial expenditure on education and focus on solving the problem of serious imbalance in the development of education in the eastern, central and western regions. Third, China's medical and health system is constantly improving, the proportion of financial expenditure on medical expenses has increased to a certain extent, but there is still a certain gap compared with developed countries. Therefore, appropriately increasing the proportion of financial expenditure on medical expenses and the proportion of health professionals will play an important role in preventing the epidemic of diseases among the social population and protecting the vulnerable groups in the society, which will directly promote the rise of CHDI in China. Fourth, while developing the economy, we should strengthen the understanding of the concept of carbon emission reduction, adjust the industrial spatial layout, improve energy efficiency, improve the energy structure and strengthen the ecological management and protection of ecological surplus areas, to reduce the per capita carbon emissions and realize the goal of green development as soon as possible. Finally, we should further expand the opening up, especially in the western region, to promote reform, development and innovation through opening and finally promote the faster development of China's CHDI.

In general, researchers have attached great importance to the issue of human development and sustainable development, but there are few literatures that combine human development with sustainability and even less with China's new development concept. This paper expands the study of China's human development index based on the new development concept and spatial relevance. This is an improvement and perfection of the HDI. However, based on this study, there are still some problems to be further discussed. For example, the spatial agglomeration of specific areas and its causes can be used as the direction of future research.

\section{Appendix}

See Table 7 


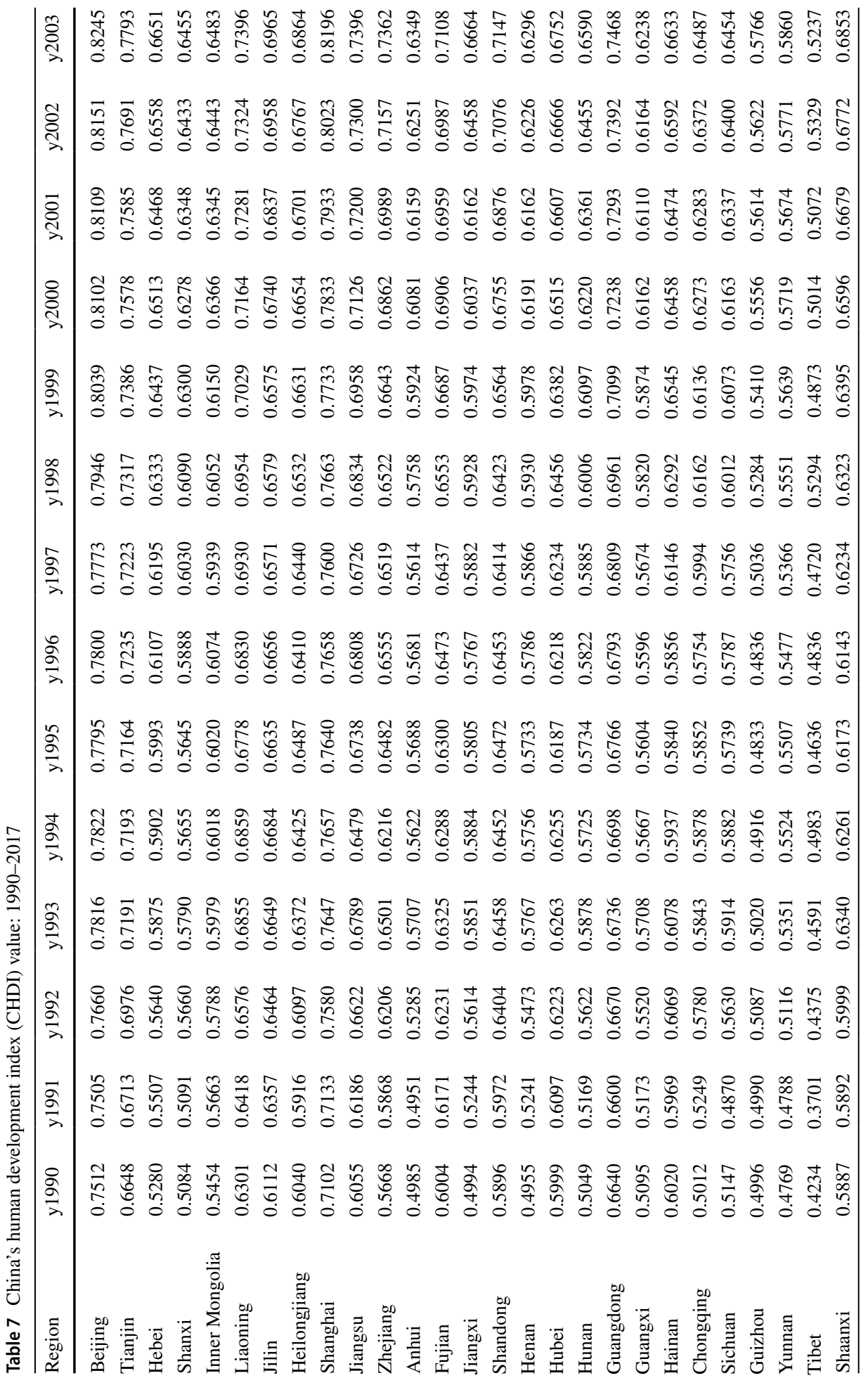




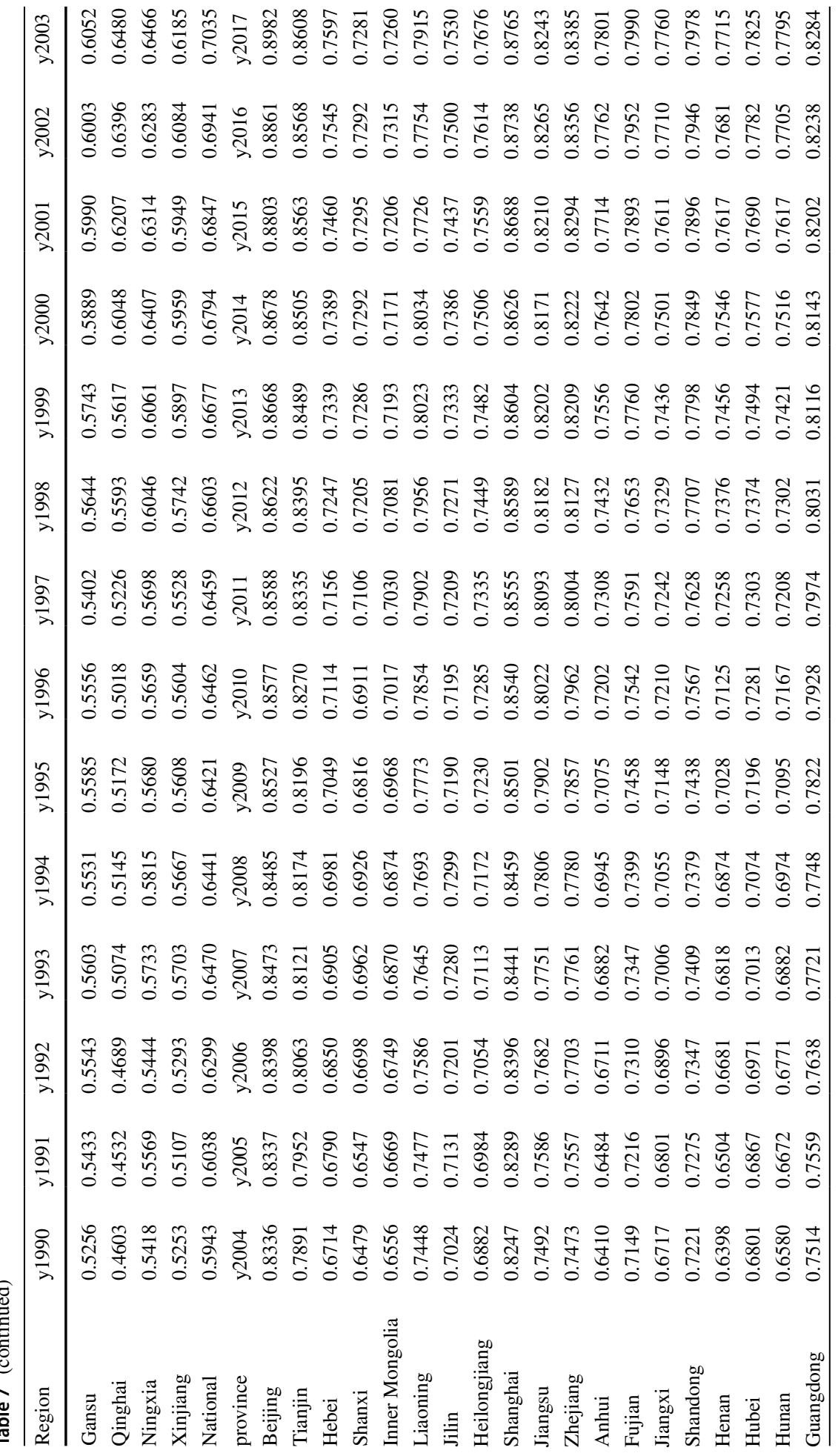




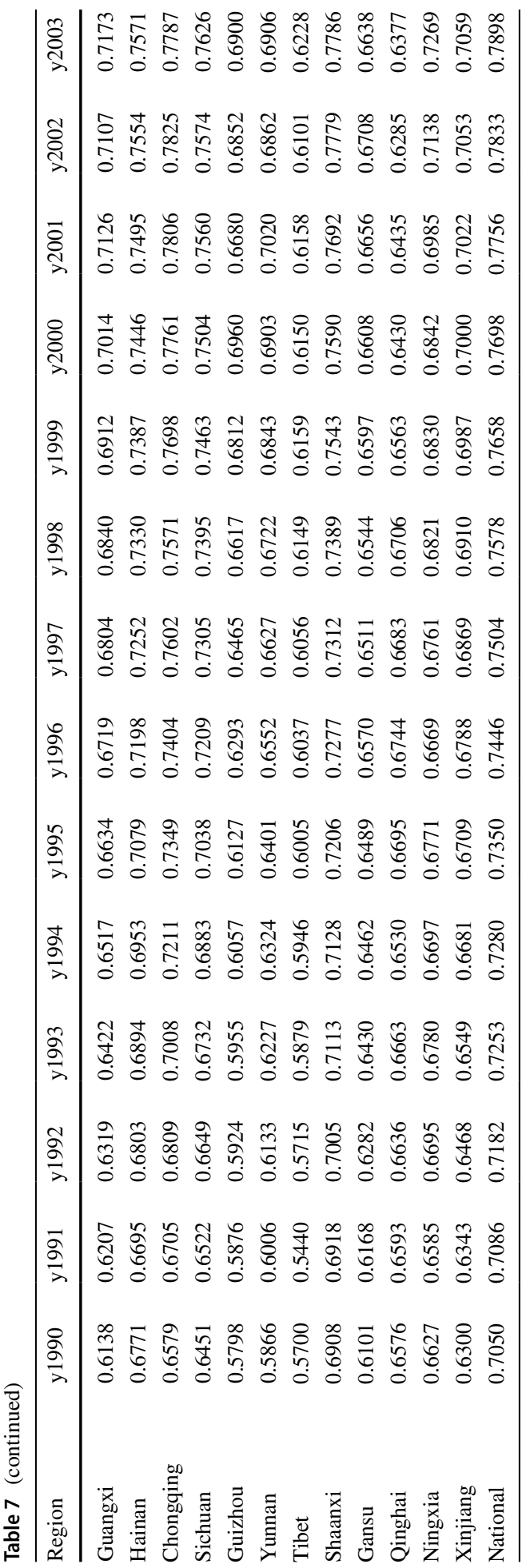


Acknowledgements Funding was provided by the China Social Science Fund Major Project (Grant No. 16ZDA010).

\section{References}

Anand, S., \& Sen A. (1994). Sustainable human development: concepts and priorities. Research Papers in Economics., 23, 1-79.

Anselin, L. (1995). Local indicators of spatial association: LISA. Geographical Analysis, 27(2), 93-115.

Anselin, L., \& Bao, S. (1997). Exploratory spatial data analysis linking SpaceStat and ArcView. Recent Developments in Spatial Analysis., 76, 35-59.

Anselin, R. S. (1991). Properties of tests for spatial dependence in linear regression models. Geographical Analysis, 23(2), 112-131.

Atkinson, A. (1970). On the measurement of economic inequality. Journal of Economic Theory, 2(3), 244-263.

Baumol, W. J. (1986). Productivity growth, convergence and welfare: What the long-run data show. American Economic Review, 76(5), 1072-1085.

Bilbao-Ubillos, J. (2013). Another approach to measuring human development: the composite dynamic human development index. Social Indicators Research, 111(2), 473-484.

Bucher, S. (2016). Sustainable development in the world from the aspect of environmental health and human development index: Regional variations and patterns. Social Science Electronic Publishing, 12(1), 117-124.

Canadell, J. G., Le Quéré, C., Raupach, M. R., et al. (2007). Contributions to accelerating atmospheric CO2 growth from economic activity, carbon intensity and efficiency of natural sinks. Proceedings of the national academy of sciences, 104(47), 18866-18870.

Chen, L. J (2008) A new test on the environmental effects of FDI Based on the panel data of 112 key cities in China. world economic research. 9; 54-59.

Chen, T. (2016). Research on the evolution and influencing factors of human development index in China. Guangzhou: South China University of Technology.

Cong, X. N. (2019). The form, nature and some misuses of coupling degree models in geography. Economic Geography, 39(4), 18-25.

Dietz, T., \& Rosa, E. A. (1997). Effects of population and affluence on CO2 emissions. Proceedings of the National Academy of Sciences, 94(1), 175-179.

Du, H. Z., Lu, X., \& Qiu, Z. R. (2017). Study on the statistical evaluation index system of the five development concepts of Binhai New Area. Tianjin Economy, 3, 8-15.

Elhorst, J. P. (2003). Specification and estimation of spatial panel data models. International Regional Science Review, 26(3), 244-268.

Elhorst, J. P. (2005). Unconditional maximum likelihood estimation of linear and log-linear dynamic models for spatial panels. Geographical Analysis, 37(1), 85-106.

Foster, J. E., Lopez-Calva, L., \& F., \& Szekely, M. . (2005). Measuring the distribution of human development: methodology and an application to Mexico. Journal of Human Development, 6(1), 5-25.

Ge, Z. Z. (2004). Evolution and innovation of development concept. Quest, 5, 83-85.

Getis, A., \& Ord, J. K. (1992). The analysis of spatial association by use of distance statistics. Perspectives on Spatial Data Analysis, 24(3), 189-206.

Han, X., \& Lee, L. F. (2013). Model selection using j-test for the spatial autoregressive model vs the matrix exponential spatial model. Regional Science \& Urban Economics., 43(2), 250-271.

Hicks, D. A. (1997). The inequality-adjusted human development index: A constructive proposal. World Development, 25(8), 1283-1298.

Holtz-Eakin, D., \& Selden, T. M. (1992). Stoking the fires? CO2 emissions and economic growth (No w4248). National Bureau of Economic Research., 67, 6-12.

Hu, Z. Q., \& Miao, C. H. (2019). An evaluation of the coordinated development of five major provincial systems in China. Statistics and Decision Making, 35(01), 96-100.

Lesage, J. P. (1999). The theory and practice of spatial econometrics. The Web Book of Regional Science., $56,183-198$.

Li, J., Tan, Q. M., \& Bai, J. H. (2010). Spatial econometric analysis of regional innovation production in China: an empirical study based on static and dynamic spatial panel models. Management World., 7 , 43-55.

Li, J., \& Wang, H. X. (2020). Ecologically sensitive construction of regional human development index and spatial convergence in China. Northwest Population, 04, 27-37. 
Li, Q (2020) Analysis of the problems and countermeasures of China's social security system. economic research guide. 428(06); 66-69

Li, X., Du, J., \& Long, H. (2020). Understanding the green development behavior and performance of industrial enterprises (GDBP-IE): Scale development and validation. International Journal of Environmental Research and Public Health, 17(5), 1716.

Li, X., \& Long, H. (2020). Research focus, frontier and knowledge base of green technology in China: metrological research based on mapping knowledge domains. Polish Journal of Environmental Studies, 29(5), 3003-3011.

Li, X., Du, J., \& Long, H. (2018). A comparative study of Chinese and foreign green development from the perspective of mapping knowledge domains. Sustainability, 10(12), 4357.

Lind, N. (2019). A development of the human development index. Social Indicators Research, 146(3), 409-423.

List, J. A., \& Catherine, Y. C. (2000). The effects of environmental regulations on foreign direct investment. Journal of Environmental Economics and Management, 40, 1-20.

Lopez-Hernandez, F. A. (2013). Second-order polynomial spatial error model: Global and local spatial dependence in unemployment in Andalusia. Economic Modelling, 33(2), 270-279.

Neumayer, E. (2001). The human development index and sustainability: A constructive proposal. Ecological Economics, 39(1), 101-114.

Neumayer, E. (2012). Human development and sustainability. Journal of Human Development and Capabilities, 13(4), 561-579.

Nikolaos, Z., Kerry, K., Yorghos, T., \& Kathryn, F. (2019). Human development over time: an empirical comparison of a dynamic index and the standard HDI. Social Indicators Research, 142, 773-798.

Ozturk, I., \& Acaravci, A. (2010). CO2 emissions, energy consumption and economic growth in Turkey. Renewable and Sustainable Energy Reviews, 14(9), 3220-3225.

Ren, D., Wu, X., \& Cao, G. G. (2020). Measurement of human development level in China and its influencing factors. Chinese Population Science., 1, 41-52.

Research group of the "Five Development Concepts Indicator System and Provincial Regional Assessment Report." (2017). Research on Provincial Regional Assessment of the Five Development Concepts. Shanghai Economy, 3, 5-13.

Sanusi, Y. A. (2008). Application of human development index to measurement of deprivations among urban households in Minna. Nigeria. Habitat International, 32(3), 1-398.

Sayed, H. A., Hamed, R., Hosny, S., et al. (2018). Avoiding ranking contradictions in human development index using goal programming. Social Indicators Research, 138(2), 405-442.

Sayed, H., Hamed, R., Ramadan, M. A. G., et al. (2015). Using meta-goal programming for a new human development indicator with distinguishable country ranks. Social Indicators Research, 123, 1-27.

Sen, A., \& Anand, S. (1994). Human development index: methodology and measurement. New York: UNDP.

Stakhovych, S., \& Bijmolt, T. H. A. (2009). Specification of spatial models: a simulation study on weights matrices. Papers in Regional Science, 88(2), 389-408.

Taner, M. T., Sezen, B., Alpkan, L., et al. (2011). Recomputation of UNDP's HDI rankings by data envelopment analysis. Emerging Markets Journal, 1(2), 21-35.

Tang, L. Z., Zhu, J. F., \& Luo, J. (2014). A new measure of real estate price influences from the perspective of macro-control. Exploration of Economic Issues, 1, 102-107.

Tiiu, P., \& Friso, S. (2006). Regional income inequality and convergence processes in the EU-25. ERSA Conference Papers., 56, 12-17.

Tofallis, C. (2013). An automatic-democratic approach to weight setting for the new human development index. Journal of Population Economics, 26(4), 1325-1345.

UNDP. (2010). Human development report 2010. Oxford University Press., 43, 215-225.

UNDP. (2016). Human development report 2016: Human development for everyone. Oxford University Press., 90, 264-268.

UNDP. (2018). Human development indices and indicators 2018 statistical update. http: //hdr. undp. Org / en/ content / human-development-indices-indicators-2018-statistical-update.

UNDP. (2019). Human development report 2019: Beyond income, beyond averages, beyond today: inequalities in human development in the 21st century. Oxford University Press., 23, 308-311.

United Nations Development Programme. (1990). Human development report 1990. Oxford University Press., 87, 10-13.

Wang, M., Kang, W. M., \& Zhang, B. (2019). Analysis of the general characteristics and driving factors of human development in China since the reform and opening up. China Population-Resources and Environment, 29(10), 70-78. 
Wang, S. Y. (2016). Driving effects and time-space differentiation of human well-being changes in China. Progress in Geoscience, 35(05), 632-643.

Yang, P. Q. (2019). Evaluation of the development level of new urbanization under the new development concept - Taking the western region as an example. Contemporary Economic Science, 41(3), 92-102.

Yang, X. H. (2017). Statistical evaluation index system construction of the "five development concepts"Shenzhen as an example. Survey Research World, 07, 3-7.

Yang, Y. H., Hu, A. G., \& Zhang, N. (2005). Alternative technology of human development index based on principal component analysis. Economic Research, 7, 4-17.

Ye, X., \& Wu, L. (2011). Analyzing the dynamics of homicide patterns in Chicago: ESDA and spatial panel approaches. Applied Geography, 31(2), 800-807.

Zhang, X. (2017). Spatial agglomeration and time-space pattern evolution of regional human development levels in China. Foreign Economic and Trade, 12, 84-88.

Zhan, X. Y., \& Cui, P. P. (2016). Measurement and evaluation of the quality of China's interprovincial economic growth-an empirical analysis based on the "Five Development Concepts." Fiscal Studies, 8, $40-53$.

Zhang, X. Y. (2018). Quality measurement of economic development in six central provinces based on the "five development concepts"- to 2016 as an example. Statistics and Management, 253(08), 45-49.

Zhou, P., Ang, B. W., \& Zhou, D. Q. (2010). Weighting and aggregation in composite indicator construction: a multiplicative optimization approach. Social Indicators Research, 96(1), 169-181.

Zhu, C. Q. (2011). Development through freedom: An extended study of the human development index in the perspective of Marx's concept of free development. People's Press., 52, 16-18.

Publisher's Note Springer Nature remains neutral with regard to jurisdictional claims in published maps and institutional affiliations. 